University of Wollongong

Research Online

Faculty of Engineering and Information

Faculty of Engineering and Information

Sciences - Papers: Part A

Sciences

$1-1-2016$

Laccase-syringaldehyde-mediated degradation of trace organic contaminants in an enzymatic membrane reactor: removal efficiency and effluent toxicity

\author{
Luong N. Nguyen \\ University of Wollongong, Inn909@uowmail.edu.au \\ Jason P. van de Merwe \\ Griffith University \\ Faisal I. Hai \\ University of Wollongong, faisal@uow.edu.au \\ Frederic D.L Leusch \\ Griffith University \\ Jinguo Kang \\ University of Wollongong, jkang@uow.edu.au
}

See next page for additional authors

Follow this and additional works at: https://ro.uow.edu.au/eispapers

Part of the Engineering Commons, and the Science and Technology Studies Commons

Research Online is the open access institutional repository for the University of Wollongong. For further information contact the UOW Library: research-pubs@uow.edu.au 


\title{
Laccase-syringaldehyde-mediated degradation of trace organic contaminants in an enzymatic membrane reactor: removal efficiency and effluent toxicity
}

\author{
Abstract \\ Redox-mediators such as syringaldehyde (SA) can improve laccase-catalyzed degradation of trace \\ organic contaminants (TrOCs) but may increase effluent toxicity. The degradation performance of 14 \\ phenolic and 17 non-phenolic TrOCs by a continuous flow enzymatic membrane reactor (EMR) at different \\ TrOC and SA loadings was assessed. A specific emphasis was placed on the investigation of the toxicity \\ of the enzyme (laccase), SA, TrOCs and the treated effluent. Batch tests demonstrated significant \\ individual and interactive toxicity of the laccase and SA preparations. Reduced removal of resistant TrOCs \\ by the EMR was observed for dosages over $50 . \mu \mathrm{g} / \mathrm{L}$. SA addition at a concentration of $10 . \mu \mathrm{M}$ \\ significantly improved TrOC removal, but no removal improvement was observed at the elevated SA \\ concentrations of 50 and $100 . \mu \mathrm{M}$. The treated effluent showed significant toxicity at SA concentrations \\ beyond 10. $\mu \mathrm{M}$, providing further evidence that higher dosage of SA must be avoided.

\section{Disciplines} \\ Engineering | Science and Technology Studies

\section{Publication Details} \\ Nguyen, L. N., van de Merwe, J. P., Hai, F. I., Leusch, F. D.L., Kang, J., Price, W. E., Roddick, F., Magram, S. F. \\ \& Nghiem, L. D. (2016). Laccase-syringaldehyde-mediated degradation of trace organic contaminants in \\ an enzymatic membrane reactor: removal efficiency and effluent toxicity. Bioresource Technology, 200 \\ 477-484.
}

\section{Authors}

Luong N. Nguyen, Jason P. van de Merwe, Faisal I. Hai, Frederic D.L Leusch, Jinguo Kang, William E. Price, Felicity Roddick, Saleh F. Magram, and Long D. Nghiem 


\section{Laccase - syringaldehyde - mediated degradation of trace organic contaminants in an enzymatic membrane reactor: Removal efficiency and effluent toxicity}

Bioresource Technology 200 (2016) 477-484

doi:10.1016/j.biortech.2015.10.054

Luong N. Nguyen ${ }^{a}$, Jason P. van de Merwe ${ }^{b}$, Faisal I. Hai ${ }^{a *}$, Frederic D.L. Leusch ${ }^{\mathrm{b}}$, Jinguo Kang ${ }^{\text {a,c }}$, William E. Price ${ }^{\mathrm{c}}$, Felicity Roddick ${ }^{\mathrm{d}}$, Saleh F. Magram ${ }^{\mathrm{e}}$, and Long D. Nghiem ${ }^{\mathrm{a}}$

${ }^{\text {a }}$ Strategic Water Infrastructure Lab, School of Civil, Mining and Environmental Engineering, University of Wollongong, Wollongong, NSW 2522, Australia.

${ }^{\mathrm{b}}$ Smart Water Research Centre, Australian Rivers Institute, School of Environment, Griffith University, QLD 4222, Australia

${ }^{\mathrm{c}}$ Strategic Water Infrastructure Lab, School of Chemistry, University of Wollongong, Wollongong, NSW 2522, Australia.

${ }^{\mathrm{d}}$ School of Civil, Environmental and Chemical Engineering, RMIT University, Melbourne, VIC 3001, Australia

${ }^{\mathrm{e}}$ Department of Civil Engineering, King Abdul Aziz University, Jeddah 21589, Saudi Arabia

*Corresponding author: Faisal I. Hai, E-mail: faisal@uow.edu.au, Ph: + 61242213054 


\section{Highlights:}

- TrOC removal by the EMR was mainly due to laccase-catalyzed degradation

- Kinetic limitations caused reduced removal of resistant TrOC for a dose over $50 \mu \mathrm{g} / \mathrm{L}$

- SA addition at a dose beyond $10 \mu \mathrm{M}$ did not improve TrOC removal by EMR

- Significant individual and interactive toxicity of laccase and SA was noted

- SA dose beyond $10 \mu \mathrm{M}$ increased the toxicity of EMR-treated effluent 


\begin{abstract}
Redox-mediators such as syringaldehyde (SA) can improve laccase-catalyzed degradation of trace organic contaminants (TrOCs) but may increase effluent toxicity. The degradation performance of 14 phenolic and 17 non-phenolic TrOCs by a continuous flow enzymatic membrane reactor (EMR) at different TrOC and SA loadings was assessed. A specific emphasis was placed on the investigation of the toxicity of the enzyme (laccase), SA, TrOCs and the treated effluent. Batch tests demonstrated significant individual and interactive toxicity of the laccase and SA preparations. Reduced removal of resistant TrOCs by the EMR was observed for dosages over $50 \mu \mathrm{g} / \mathrm{L}$. SA addition at a concentration of $10 \mu \mathrm{M}$ significantly improved TrOC removal, but no removal improvement was observed at the elevated SA concentrations of 50 and $100 \mu \mathrm{M}$. The treated effluent showed significant toxicity at SA concentrations beyond $10 \mu \mathrm{M}$, providing further evidence that higher dosage of SA must be avoided.
\end{abstract}

Keywords: laccase; syringaldehyde; trace organic contaminants (TrOCs); toxicity; enzymatic membrane reactor $(\mathrm{EMR})$ 


\section{Introduction}

Laccases (EC 1.10.3.2) are oxidoreductase enzymes that can effectively oxidize a range of aromatic compounds such as phenols and aromatic amines (Cañas \& Camarero, 2010; d'Acunzo et al., 2006) using atmospheric oxygen as the terminal oxidant. Detection of trace organic contaminants (TrOCs) including pharmaceutically active compounds, industrial chemicals, pesticides, and natural and artificial hormones in the aquatic environment has raised considerable concern due to their potential effects on human health and the ecosystem (Schwarzenbach et al., 2006). Biodegradation of TrOCs by means of enzymes such as laccases has recently attracted much attention (Hai et al., 2013). A significant barrier against the application of laccase in a continuous flow wastewater treatment process, however, is the wash out of the enzyme along with the treated effluent. The loss of laccase in the treated effluent may be effectively prevented by coupling a membrane to the bioreactor, thus forming an enzymatic membrane reactor (EMR). Only a handful of studies have assessed TrOC removal performance in continuous flow EMRs (Ba et al., 2014; Escalona et al., 2014; Nguyen et al., 2015). TrOC degradation performance of EMRs depends on various factors including the chemical structure of TrOCs. For example, in a previous study, phenolic compounds were more effectively removed than the non-phenolic TrOCs (Nguyen et al., 2015).

Addition of a redox mediator may broaden the substrate spectrum of laccase. Mediators are lowmolecular weight substrates of laccase that can act as "electron carriers" between the enzyme and the target pollutant. These include both synthetic (e.g., 1-hydroxybenzotriazole (HBT) and 2,2'azino-bis(3-ethylbenzothiazoline-6-sulphonic acid (ABTS)) and natural (e.g., syringaldehyde (SA) and $P$-coumaric acid) mediators. Owing to the cost and potential toxicity of the synthetic mediators, the use of laccase in combination with natural mediators has been proposed as an 
alternative (Camarero et al., 2007; Xu et al., 2000). While the natural mediators have shown case-specific efficiency in enhancing TrOC degradation (Nguyen et al., 2014; Yang et al., 2013), certain studies have raised concern about elevated toxicity in the effluent even when natural mediators are used to enhance laccase-catalyzed degradation of pollutants. For example, Fillat et al. (2010) observed increased toxicity in effluent when they used the natural mediator SA to enhance the laccase-catalyzed bleaching of flax pulp. Although there is a lack of consensus regarding the mechanisms of such toxicity, it has been proposed that the highly reactive radical species generated via the laccase - SA system, which aid in enhancing pollutant degradation, may cause toxicity (Fillat et al., 2010; Khlifi et al., 2010). In addition, previous studies employing laccase - SA combination to degrade resistant compounds including TrOCs seem to have overlooked the reported inhibitory impact of SA itself (in absence of laccase) on microbes, for example, those capable of biofuel production from lignocellulosic biomass (Richmond et al., 2012; Yu et al., 2014). It is also important to take into consideration the fact that the laccase system forms a part of the defense system in certain eukaryotes - a notable example being the expression of antibacterial activity of some white-rot fungi (de Boer et al., 2010). Although probably not to the same extent as SA, laccase preparations may also contribute to effluent toxicity as assessed by common single bacterium based aquatic toxicity assays. Notably, most of the available studies on TrOC degradation by laccase - SA system has been carried out in batch incubation tests. Moreover, to date no study has systematically compared the toxicity of laccase and SA preparations separately or in mixture. Particularly, the impact of SA-dose on TrOC removal efficiency by EMR and effluent toxicity remains to be elucidated.

The objective of this study was to assess the performance of an EMR at degrading 31 selected TrOCs at different TrOC and SA loadings, with a special focus on the toxicity of the treated 
effluent. In discussing the TrOC degradation profiles, due consideration has been provided to the phenolic moiety and other important features of TrOC structure. Effluent toxicity following EMR treatment may be due to generation of toxic by-products and/or due to the afore-mentioned laccase - SA mechanisms. A series of batch tests assessing the toxicity of pure solutions of laccase and SA preparations as well their mixture helped to provide insights into this aspect. Through a systematic consideration of both TrOC removal efficiency and effluent toxicity, an optimal SA dosage range was recommended.

\section{Materials and methods}

\subsection{Trace organic contaminants}

A set of 31 TrOCs, including ten pharmaceuticals, seven pesticides, five steroid hormones, three industrial chemicals, two phytoestrogens, and four personal care products was examined. Key properties of these compounds are listed in Supplementary Data Table S1. These TrOCs were selected in view of their widespread occurrence in wastewater and wastewater-impacted water bodies and represents different molecular properties such as phenolic vs. non-phenolic moieties and electron donating vs. withdrawing functional groups. All compounds were purchased from Sigma-Aldrich (Australia). A stock solution of the TrOCs was prepared at a concentration of $1 \mathrm{~g} / \mathrm{L}$ (each) in methanol $(99.9 \%)$, stored at $-18{ }^{\circ} \mathrm{C}$ and used within a month of preparation.

\subsection{Laccase solution and mediator}

Laccase, purified from genetically modified A. oryzae, was obtained from Novozymes Australia Pty Ltd. The laccase solution contains water (66\%), propylene glycol (25\%), glucose (4\%), laccase $(3 \%)$ and glycine $(2 \%)(\mathrm{w} / \mathrm{w})$. It has a molecular weight, density and activity (measured using 2,6-dimethoxy phenol, DMP, as substrate) of $56 \mathrm{kDa}, 1.12 \mathrm{~g} / \mathrm{mL}$, and $150,000 \mu \mathrm{M}_{(\mathrm{DMP})}$ /min, respectively. 
The mediator SA was used in this study. SA was purchased from Sigma-Aldrich (Australia). A stock solution $(50 \mathrm{mM})$ of SA was prepared in Milli-Q water, stored at $4{ }^{\circ} \mathrm{C}$ and used within a month of preparation.

\subsection{Assessment of laccase and SA toxicity}

The bacterial luminescence toxicity screen (BLT-Screen) method described by van de Merwe and Leusch (2015) was used to investigate the individual and interactive toxicity of laccase and SA. In two separate 96-well plates, SA was serially diluted (1:2) along columns 3-11, ranging from 1000 to $4 \mu \mathrm{M}$, and laccase was serially diluted (1:2) down rows 'A'- ' $\mathrm{G}$ ', ranging from 750 to $12 \mu \mathrm{M}_{(\mathrm{DMP})} / \mathrm{min}$. $100 \mu \mathrm{L}$ from each plate (final volume of $200 \mu \mathrm{L}$ per well) was then added to a white 96-well microplate (Greiner Bio-One, Austria), resulting in different combinations of laccase and SA concentrations, ranging from 500 to $2 \mu \mathrm{M}$ for $\mathrm{SA}$ and 375 to $6 \mu \mathrm{M}_{(\mathrm{DMP})} / \mathrm{min}$ for laccase. To test toxicity of SA and laccase independent of each other, column 12 contained phosphate buffered saline assay media with laccase only and row ' $\mathrm{H}$ ' contained phosphate buffered saline assay media with SA only, at the afore-mentioned concentration ranges. A serially diluted (1:5) standard curve of the reference compound, pentachlorophenol (rows 'A''G'), and a negative control Milli-Q water (row 'H'), all in phosphate buffered saline assay media, were included in duplicate in the first two columns of the plate for quality control. Five microliters of the luminescent bacteria, Photobacterium leiognathi (from a cryopreserved aliquot) was then added to each well using a multi-channel pipette. Exactly 30 mins later the luminescence of each well was measured on a Fluostar plate reader (BMG Labtech, Germany). The experiment was run on two separate occasions and the mean $\%$ inhibition of luminescence was calculated for each combination of laccase and SA, using the following equation from van de Merwe and Leusch (2015): 


$$
\% \text { Inhibition }=\left[1-\left(\frac{\text { luminescence }_{\text {sample }}}{\text { luminescence }_{\text {control }}}\right)\right] \times 100 \quad \text { Equation } 1
$$

For each SA: laccase ratio (which ranged from 0.01 to 21.3) the inhibition of luminescence was plotted against the sum of SA and laccase concentrations and the $\mathrm{IC}_{50}$ (concentration that causes $50 \%$ inhibition of bacterial luminescence) was calculated from the straight line regression. The $\%$ inhibition was also plotted against SA only and laccase only concentrations and the $\mathrm{IC}_{50}$ values for SA and laccase were calculated from the straight line regressions (see Figure 1). These $\mathrm{IC}_{50}$ values were further used in the assessment of interactive toxicity (see below).

The interactive toxicity of laccase and SA was analysed using an isobologram, following methods originally described by Gaddum (1949) and Loewe (1953), and implemented widely in mixture toxicity research (e.g., (Mori et al., 2015; Sørensen et al., 2007). For each SA : laccase ratio individual toxic units (TUs) were calculated in Microsoft Excel (Microsoft Corp, Redmond, WA, USA) for both laccase and SA as :

$$
\mathrm{TU} i=\left(\mathrm{p} i \times \mathrm{IC}_{50} i\right) / \mathrm{IC}_{50} \quad \text { Equation } 2
$$

where

$i=$ a specific $\mathrm{SA}$ : laccase ratio,

$\mathrm{p} i=$ the proportion of the total concentration due to the compound (e.g., p $i_{\text {laccase }}=\mathrm{C}_{\text {laccase }} /$

$\left(\mathrm{C}_{\text {laccase }}+\mathrm{C}_{\mathrm{SA}}\right)$, where $\mathrm{C}_{\text {laccase }}$ and $\mathrm{C}_{\mathrm{SA}}$ are the concentration of laccase and $\mathrm{SA}$ in the mixture, respectively),

$\mathrm{IC}_{50} i=$ the $\mathrm{IC}_{50}$ at the particular laccase:SA ratio $i$, and 
$\mathrm{IC}_{50}=$ the $\mathrm{IC}_{50}$ of each compound individually determined from the concentration-effect curve of single compounds (i.e., $380 \mu \mathrm{M}$ and $370 \mu \mathrm{M}_{(\mathrm{DMP})} / \mathrm{min}$ for SA and laccase, respectively; see Section 3.1).

Laccase and SA interactive toxicity was analysed by plotting $\mathrm{TU}_{\text {laccase }} v s$. $\mathrm{TU}_{\mathrm{SA}}$ and examining the position of the resulting isobole. In addition, a contour map of toxicity, plotting laccase activity $v s$. SA concentration was generated in SigmaPlot (Systat Software Inc, San Jose, CA, USA).

\subsection{Enzymatic membrane reactor}

The lab scale EMR set up has been described in a previous study (Nguyen et al., 2015). Briefly, a hollow fiber membrane module (Microza Membranes, Pall Corporation, NSW, Australia) with a molecular weight cut off of $6 \mathrm{kDa}$ was submerged in a $1.5 \mathrm{~L}$ (active volume) glass reactor. This membrane was selected based on initial trials confirming complete retention of the enzyme. The membrane module was made of polyacrylonitrile, and had a surface area of $0.19 \mathrm{~m}^{2}$. Laccase (2 $\mathrm{mL}$ ) was added from stock solution to 1.5 L Milli-Q water. This resulted in an enzymatic activity of $180 \mu \mathrm{M}_{(\mathrm{DMP})} / \mathrm{min}$ in the reactor. Laccase activity was maintained at a range of 160 to 180 $\mu \mathrm{M}_{(\mathrm{DMP})} /$ min by the addition of $400 \mu \mathrm{L}$ of the commercial laccase solution per liter of the reactor volume every $12 \mathrm{~h}$ (equivalent to a laccase dose of $46 \mathrm{mg} / \mathrm{L} \mathrm{d}$ ) following a previously developed protocol (Nguyen et al., 2015). A peristaltic pump was used to operate the membrane intermittently ( 8 min on and $1 \mathrm{~min}$ off) at an average flux of $1.1 \mathrm{~L} / \mathrm{m}^{2} \mathrm{~h}$. This resulted in a hydraulic retention time (HRT) of $8 \mathrm{~h}$. In this study, the EMR was operated under six different combinations of TrOC and SA concentrations (Supplementary Data Table S2) to assess their impacts on both the removal efficiency and effluent toxicity. Feed solution containing TrOCs at concentration of 5,50 and $100 \mu \mathrm{g} / \mathrm{L}$ in Milli-Q water was prepared daily and fed continuously to 
the reactor. SA solution was continuously fed to the reactor at a final concentration of 10,50 or $100 \mu \mathrm{M}$. A low flux was applied to minimize membrane fouling, thus allowing the focus of the study to be on the removal performance. The EMR was operated for a period of $9 \mathrm{x}$ HRT in each run. Duplicate samples of influent and permeate were collected at three sampling events over the operation period. The samples were collected after a period of 3xHRT following the start of operation to ensure that steady removal performance was established. At the end of each run, duplicate samples were collected to quantify TrOC concentration in the reactor supernatant. Additionally, the membrane module was taken out of the reactor and subjected to backwashing with $1 \mathrm{~L}$ Milli-Q water at a flux of $5 \mathrm{~L} / \mathrm{m}^{2} \mathrm{~h}$. The backwash solution was collected to measure any TrOC released during the backwashing. Milli-Q water backwashing was adequate to retrieve the original transmembrane membrane pressure $(1 \mathrm{kPa})$ before a new run. There was negligible increase in TMP during each run.

\subsection{Analytical methods}

\subsubsection{Laccase activity and toxicity assay}

Laccase activity was measured by observing the change in absorbance $468 \mathrm{~nm}$ due to oxidation of 2,6-dimethoxyl phenol (DMP) by laccase and expressed in $\mu \mathrm{M}_{(\mathrm{DMP})} / \mathrm{min}$. Details of laccase activity assay has been reported in a previous study (Nguyen et al., 2014). Bacterial toxicity of influent and effluent (permeate) was analyzed in duplicate by measuring bioluminescence inhibition in Photobacterium leiognathi, and expressed as relative Toxic Unit (rTU), following the bacterial luminescence toxicity screen (BLT-Screen) methods previously described by van de Merwe and Leusch (2015). The rTU was calculated as $\mathrm{rTU}=1 /\left(\mathrm{IC}_{20}\right)$, where $\mathrm{IC}_{20}$ is the concentration of the sample required to inhibit bacterial luminescence by $20 \%$. The $\mathrm{IC}_{20}$ was 
determined by linear regression of the toxicity response $v s$. relative sample enrichment within the linear range of the concentration-effect curve (up to $40 \%$ inhibition).

\subsubsection{TrOC analysis}

The concentrations of the TrOCs were measured by a previously reported analytical technique involving solid phase extraction, derivatisation and quantitative determination by a Shimadzu GC/MS (QP5000) system (Hai et al., 2011). The absolute and relative SPE recovery for the TrOCs was above $80 \%$ and varied from 2 to $5 \%$ between each analysis. The quantitative detection limits of this analytical method were compound specific and in the range 1 to $20 \mathrm{ng} / \mathrm{L}$ (Supplementary Data Table S1).

The removal efficiency was calculated as shown in Equation 3:

$$
R=100 \times\left(1-\frac{\left(C_{e f f} \times V_{e f f}\right)}{\left(C_{i n f} \times V_{i f f}\right)}\right) \quad \text { Equation } 3
$$

where $\mathrm{C}_{\text {inf }}$ and $\mathrm{V}_{\text {iff }}$ are influent concentration (ng/L) of the TrOCs and volume (L), respectively. $\mathrm{C}_{\text {eff }}$ and $\mathrm{V}_{\text {eff }}$ are effluent (permeate) concentrations (ng/L) of the TrOCs and volume (L) respectively.

TrOC biodegradation during EMR treatment was calculated using the following mass balance equation:

$C_{\text {inf }} \times V_{\text {inf }}=C_{e f f} \times V_{e f f}+C_{a d s} \times V_{a d s}+C_{\text {sup }} \times V_{\text {sup }}+$ biodegradation Equation 4

Where, $\mathrm{C}_{\text {inf }}$ and $\mathrm{V}_{\text {iff }}$ are influent concentration (ng/L) and volume (L). $\mathrm{C}_{\text {eff }}$ and $\mathrm{V}_{\text {eff }}$ are effluent concentration (ng/L) and volume (L). $\mathrm{C}_{\mathrm{ads}}$ and $\mathrm{V}_{\mathrm{ads}}$ are the concentration of TrOCs adsorbed on membrane (ng/L) and volume of cleaning solution during the membrane backwashing with Milli-Q water. $\mathrm{C}_{\text {sup }}$ and $\mathrm{V}_{\text {sup }}$ are reactor supernatant concentration (ng/L) and volume (L), 
respectively. The mass of TrOCs adsorbed on membrane was estimated form $1 \mathrm{~L}$ of cleaning solution during the membrane backwashing with Milli-Q water.

\section{Results and discussion}

3.1 Toxicity of utilized laccase and mediator

\subsubsection{Toxicity of the individual solutions}

Pure solutions of laccase and SA were both toxic to the luminescent bacteria, Photobacterium leiognathi, and showed very similar relationships with concentration (Figure 1). Using the regression equations presented in Figure 1, the $\mathrm{IC}_{20}$ values (limit of quantification of the BLTScreen; van de Merwe and Leusch 2015) were $147 \mu \mathrm{M}_{(\mathrm{DMP})} / \mathrm{min}$ and $153 \mu \mathrm{M}$ of laccase and SA, respectively. In addition, more relevant to the calculations of interactive toxicity, the $\mathrm{IC}_{50}$ (i.e., concentration required to inhibit $50 \%$ of bacterial luminescence) for laccase and SA was 370 $\mu \mathrm{M}_{(\mathrm{DMP})} / \mathrm{min}$ (Figure $1 \mathrm{a}$ ) and $380 \mu \mathrm{M}$ (Figure $1 \mathrm{~b}$ ), respectively. In nature, the laccase system has been previously described to protect plant-pathogen fungi from the toxic phytoalexins and tannins in the host plant (Pipe et al., 2000) or to protect invertebrates (e.g., crustaceans) from invading microorganisms (Luna-Acosta et al., 2011). However, this is the first report regarding aquatic toxicity (measured in terms of inhibition of bacterial luminescence) of a purified laccase

preparation. Notably, Kim et al. (2006b) reported negligible toxicity of a laccase purified from $T$. versicolor. They, however, carried out the toxicity assay with a much lower laccase activity of $1.5 \mu \mathrm{M}_{(\mathrm{ABTS})} / \mathrm{min}$, and also used a different luminescent bacterium (i.e., Photobacterium phosphoreum). The laccase preparation used in this study contained preservatives such as propylene glycol, glucose and glycine $(25 \%, 4 \%$ and $2 \%, w / w$, respectively), which are generally 
considered non-toxic. The toxicity of laccase observed in the present study is therefore most likely attributed to the damage to bacterial cells via laccase-catalyzed reactions.

\section{[FIGURE 1]}

SA is a naturally occurring lignocellulose degradation product, which is thought to inhibit growth of a range of microbes including yeast, bacteria and algae (Richmond et al., 2012; Yu et al., 2014). For example, Richmond et al. (2012) reported that SA hampers metabolism of Clostridium beijerinckii (NCIMB 8052) by inhibiting the expression and activity of coenzyme A transferase during its growth. However, as a notable omission, most available studies investigating pollutant removal via SA-enhanced laccase systems did not investigate SA toxicity, and assumed that SA was non-toxic due to its natural origin (Camarero et al., 2007; Cañas \& Camarero, 2010).

\subsubsection{Toxicity of laccase - SA mixture}

Oxidation of mediators (in this case SA) generates highly reactive radical species, which can degrade target pollutants (Fillat et al., 2010; Kim \& Nicell, 2006a). Kim and Nicell (2006a) suggested that radicals formed due to oxidation of mediators may also interact with vitally important biomolecules and result in cytotoxic effects. Thus, it was anticipated that the laccase SA mixtures prepared here would exhibit increased toxicity. Indeed a strong synergism between laccase and SA in terms of the toxicity of the mixture was observed (Figure 2). As noted in Section 2.3, the interactive toxicity of laccase and SA was analysed using an isobologram i.e., $\mathrm{TU}_{\text {laccase }} v s . \mathrm{TU}_{\mathrm{SA}}$ plot (Figure 2a). Chemicals with common modes of action can act jointly to produce combination effects that are larger than the effects of each mixture component applied individually. These effects can be described by 'dose or concentration addition'. In this study, all 
the points in the isobologram stayed below the 'concentration addition line' or in the 'zone of synergism' (Figure 2a), confirming that the combination of laccase and SA had a synergistic effect on the tested microorganism (i.e., Photobacterium leiognathi). Through a Microtox assay using Vibrio fischeri, Fillat et al. (2010) observed an 18 fold increase in effluent toxicity due to laccase - SA interaction during bleaching of flax pulp by laccase (the pulp contains SA). Maruyama et al. (2007) observed effective degradation of imazalil (a postharvest fungicide) by laccase in the presence of 4-hydroxybenzoic acid (a natural mediator) but toxicity of the effluent against mouse fibroblast L929 cells revealed toxicity of 4-hydroxybenzoic acid. These previous investigations were conducted in batch mode and under selected dosages of laccase and the mediator. The data reported in the current study demonstrates this phenomenon in a more comprehensive manner i.e., over a broader range of concentrations of laccase and SA, and in both batch (Section 3.1.2) and continuous flow (Section 3.6) modes. The toxicity contour plot shown in Figure $2 \mathrm{~b}$ demonstrates further the strong impact of the presence of laccase on SA toxicity. Additional discussion on the effluent toxicity during the treatment of TrOCs by EMR has been presented in Section 3.6.

[FIGURE 2]

\subsection{Overall TrOC removal by EMR}

The performance of the EMR in removing TrOCs was evaluated at different combinations of TrOC concentration (from 5 - $100 \mu \mathrm{g} / \mathrm{L}$ ) and SA concentration (from 0 - $100 \mu \mathrm{M}$ )

(Supplementary Data Table S2). TrOC removal performance at a TrOC concentration of $5 \mu \mathrm{g} / \mathrm{L}$ and SA concentration of 0 and $10 \mu \mathrm{M}$ is first discussed to illustrate the general trend (Figure 3). Laccase can efficiently degrade phenolic compounds, particularly the polyphenols (Yang et al., 2013). It was not a surprise that the EMR could remove all phenolic TrOCs. Of all 14 phenolic 
compounds, the EMR-laccase could remove 70 to $100 \%$ of eight compounds, 40 to $70 \%$ of five compounds and $20 \%$ of one compound. The low removal of five compounds (40-70\%) and one compound (20\%) may be due to steric hindrance which prevents the reaction between laccase and the compounds. For example, d'Acunzo et al. (2006) observed that $\beta$-naphthols and 2,4,6trichlorophenol were not oxidized by laccase due to steric hindrance. The presence of electron withdrawing group at the ortho position to the $-\mathrm{OH}$ group hinders the approach of the substrate to the active sites of laccase (d'Acunzo et al., 2006), which may explain the low removal of salicylic acid and pentachlorophenol in the current study. On the other hand, except for benzophenone, amitriptyline, octocrylene and diclofenac, the non-phenolic TrOCs were poorly removed by the EMR. The efficient removal of diclofenac could be due to its direct oxidation by laccase via the aniline group in its structure (Lloret et al., 2010). Laccase could mediate oxidative cleavage of carbonyl group in ketone such as [N,N-dimethylaminophenyl][Nmethyaminophenyl] benzophenone (Parshetti et al., 2011), which may explain the high removal of benzophenone in this study. Amitriptyline and octocrylene were previously noted to be persistent to laccase oxidation in batch tests (Nguyen et al., 2014; Nguyen et al., 2015).

However, their high removal by the EMR in this study may be due to their retention by a laccase gel layer (formed on the membrane) and subsequent degradation, as further discussed in Section 3.5. It is also noted that the formation of enzyme gel layer could lead to the membrane fouling. For example, Chhabra et al. (2009) observed a 10\% drop in membrane flux after 15 days of EMR operation. However, under the operating conditions (low flux and short period) in this study, TMP was negligible.

[FIGURE 3] 
Addition of SA at $10 \mu \mathrm{M}$ led to the following changes in TrOC removal (Figure 3): i) higher removal of previously well-degraded TrOCs (e.g., estriol, 17 $\alpha$-ethinylestradiol, 17 $\beta$-estradiol, and 4-tert-butylphenol), ii) improved degradation of some phenolic TrOCs (e.g., estrone, bisphenol A, salicylic acid, formononetin, pentachlorophenol, and enterolactone) originally resistant to laccase-EMR treatment, and iii) degradation of a few additional non-phenolic TrOCs (e.g., metronidazole, gemfibrozil, and ketoprofen). The phenoxyl radicals formed during the oxidation of SA by laccase may act as 'electron shuttles' between laccase and the target compound (Xu et al., 2000). These radical species may have higher redox potential than laccase and/or overcome the steric hindrance due to their small size, and thus improve TrOC removal. Indeed the redox-potential of the laccase solution increased significantly (from $270 \mathrm{mV}$ to 530 $\mathrm{mV}$ ) due to SA addition at $10 \mu \mathrm{M}$ in this study. This is consistent with the observation of Weng et al. (2012), who reported only batch test data and monitored removal of a few TrOCs.

A notable observation made during the initial run was that even with the addition of SA $(10 \mu \mathrm{M})$, the laccase-EMR could degrade only a limited number of non-phenolic compounds (Figure 3). Previous batch studies have reported that both abundance and stability of the oxidized intermediates from the mediators affect TrOC degradation. Mediator concentration can influence these (Camarero et al., 2007; Nguyen et al., 2014). Thus, there may be scope of optimizing SA dosages. Sections 3.3 and 3.4 present further discussion on this aspect.

\subsection{Impact of TrOC concentrations on EMR performance}

TrOC removal by the EMR was further evaluated at higher influent TrOC concentrations (i.e., 50 and $100 \mu \mathrm{g} / \mathrm{L}$ ) but with the same SA dose of $10 \mu \mathrm{M}$ and laccase activity of $180 \mu \mathrm{M}_{(\mathrm{DMP})} / \mathrm{min}$ as in the first trial (Section 3.2). Except pentachlorophenol, formononetin and enterolactone, which showed 25 to $40 \%$ improvement in removal, a similarly high removal efficiency of the phenolic 
TrOCs was noted irrespective of their concentration in the influent (Supplementary Data Figure S3). Overall 80-100\% removal of the phenolic TrOCs was achieved by the EMR. Therefore, further discussion in this section focuses on the removal of the non-phenolic TrOCs.

The removal efficiency of a number of non-phenolic TrOCs increased when influent TrOC concentration was increased from 5 to $50 \mu \mathrm{g} / \mathrm{L}$ (Figure $4 \mathrm{a}$ ). However, the removal of a few compounds, namely, ametryn, naproxen and primidone decreased when the influent TrOC concentration was further increased to $100 \mu \mathrm{g} / \mathrm{L}$, probably due to kinetic limitations. In general, the rate of an enzymatic reaction increases with substrate concentration, but eventually reaches a plateau as all the active sites of the enzyme become occupied (Cristóvão et al., 2008). Thus beyond a certain substrate concentration, the percentage removal efficiency drops. The drop in removal of ametryn, naproxen and primidone at their higher influent concentrations signifies particular resistance of these TrOCs to degradation by laccase-SA system. This is the first study to assess the impact of influent concentration on the removal of the non-phenolic TrOCs investigated.

[FIGURE 4]

\subsection{Impact of SA concentration on EMR performance}

High removal of the phenolic TrOCs was already obtained at an SA dose of $10 \mu \mathrm{M}$ (Supplementary Data Figure S3), and the removal efficiencies remained largely unaltered at the higher SA dosages of 50 and $100 \mu \mathrm{M}$ (data not shown). Similarly, except for 20-35\% improvement in the removal of diclofenac, metronidazole and primidone, virtually no change in the removal of the non-phenolic TrOCs was observed after increasing SA concentration from 10 to $50 \mu \mathrm{M}$ (Figure 4b). Furthermore, 10-20\% decrease in the removal of a few TrOCs was noted 
when the SA concentration was increased from 50 to $100 \mu \mathrm{M}$. Our results are in line with the general trend observed in the available batch studies (Mizuno et al., 2009; Nguyen et al., 2014) that pollutant degradation by laccase may reach a saturation point beyond a certain mediator concentration, but shows this systematically for the first time in the context of a continuous flow EMR.

In the current study, the laccase activity in the EMR was maintained at the same level during operations with different SA dosages $(10,50$ and $100 \mu \mathrm{M})$. Rate limitation of SA oxidation by laccase may have had occurred under higher SA concentrations because the rate of the reaction would not increase with the mediator concentration when it is already present at sufficiently high levels to saturate all the reactive sites of the enzyme. Thus, increasing SA concentration beyond $50 \mu \mathrm{M}$ did not improve TrOC removal efficiency (Figure 4b). Furthermore, reduced degradation of a few target compounds at an SA dose of $100 \mu \mathrm{M}$ may be because, at excessive mediator concentrations, high levels of reactive radicals are quickly produced, which have a tendency to react with each other rather than with the pollutant (Margot et al., 2015). Two points are conceivable from the information depicted in Figures 4a and 4b: (i) an SA dose greater than 10 $\mu \mathrm{M}$ is not required for influent $\mathrm{TrOC}$ concentrations not exceeding $50 \mu \mathrm{g} / \mathrm{L}$, and (ii) even at an influent $\operatorname{TrOC}$ concentration of $100 \mu \mathrm{g} / \mathrm{L}$, improvement in removal of a limited number of TrOCs would be achieved if the SA dose was increased to $50 \mu \mathrm{M}$. Applying the lowest possible SA dose would be economical, and additionally it may avoid SA-induced toxicity of treated effluent (discussed in Section 3.6).

\subsection{Fate of TrOCs}

TrOC removal during EMR treatment may occur due to enzymatic degradation, adsorption on and subsequent rejection by the membrane, volatilization and photolysis (Mizuno et al., 2009; 
Nguyen et al., 2014). Volatilization was expected to be negligible because of the very low vapor pressure or Henry's constant $(\mathrm{H})$ and low 'H/log D ratio' (Supplementary Data Table S1) of the selected TrOCs. TrOC photolysis was avoided by covering the EMR with aluminum foil. On the other hand, given the relative sizes, the ultrafiltration membrane used in this study was not capable of directly retaining any TrOCs. However, the laccase molecules retained by a membrane can form a gel layer on it (Modin et al., 2014), which may retain the TrOCs in the reactor and facilitate their further degradation. The following observations made in the current study validate this hypothesis: (i) a laccase gel layer on the membrane was evident by a significant laccase activity in the membrane backwash solution (the measured laccase activity indicated an accumulation of approximately $0.24 \mathrm{~g}$ active laccase per $\mathrm{m}^{2}$ membrane surface), (ii) TrOCs were detected at low but discernible concentrations in the backwash solution (Supplementary Data Figure S4), evidencing TrOC retention by the laccase layer, and (iii) the ratio of concentration of TrOCs in effluent and supernatant was below 1 for a number of TrOCs (data not shown), indicating an additional 'removal' by the laccase gel layer. Overall, a mass balance analysis confirmed that, irrespective of the TrOC and SA concentrations, TrOC removal by the EMR was mainly due to biodegradation (Figure 5).

[FIGURE 5]

The observations regarding the prime role of biodegradation in TrOC removal by EMR is generally consistent with a previous study (Nguyen et al., 2015), but the current study confirms this trend over a range of TrOC and SA concentrations. An additional aspect captured by the current investigation is that higher SA concentration did not necessarily correspond to the higher percentage of biodegradation. For example, most non-phenolic TrOCs were detected in higher concentrations in reactor supernatant for an SA dose of $100 \mu \mathrm{M}$ than for $50 \mu \mathrm{M}$ (Figure 5). This 
further strengthens the point highlighted in the previous section regarding the importance of mediator dose selection.

\subsection{Toxicity of EMR-treated effluent}

\section{[FIGURE 6]}

At the concentrations tested, TrOC solutions (i.e., 31 TrOCs in Milli-Q water) showed negligible toxicity, and no increase in toxicity was also observed in EMR effluent in the absence of SA (data not shown). On the other hand, consistent with the batch test data showing SA-induced toxicity (Figure 1b), the toxicity of the influent to the EMR during the laccase-SA investigations (i.e., TrOC and SA in Milli-Q) increased with SA concentration. For example, a toxicity of 11.1 rTU was recorded in case of an SA dose of $100 \mu \mathrm{M}$, compared to a toxicity of $2.5 \mathrm{rTU}$ at an SA dose of $10 \mu \mathrm{M}$ (Figure 6). Two notable observations were made regarding the toxicity of the EMR effluent: (i) the toxicity of the influent containing 10 and $50 \mu \mathrm{M}$ SA was significantly decreased after the EMR treatment (2.5 vs. below detection limit, and 10.5 vs $7.0 \mathrm{rTU}$, respectively), but (ii) an increase in the toxicity of the effluent was observed when SA was added at a concentration of $100 \mu \mathrm{M}(11.1$ vs $19.9 \mathrm{rTU})$ (Figure 6). An SA concentration - specific toxicity was also reported in a previous batch study wherein a crude enzyme extract (mainly laccase from T.versicolor) and SA were used (Nguyen et al., 2014). Highly reactive phenoxyl radicals are produced due to oxidation of SA by laccase. These radical species can be consumed as they react with TrOCs (Margot et al., 2015). However, due to continuous addition of SA in excess, copious amount of reactive radical species are likely to be produced. The unconsumed radicals and SA can permeate through the membrane to the treated effluent and increase its toxicity. It is also important to note that the degradation by-product from the EMR with laccase only and EMR-laccase-SA may be different. The difference of by-product may cause an elevated 
toxicity in case of EMR-laccase-SA. However, quantitative or identical analysis of by-product was under the scope of this study. Nevertheless, the SA dose must be carefully controlled, particularly because higher SA dose did not necessarily achieve better TrOC removal (Figure 4b) but heighten toxicity in the effluent,

\section{Conclusions}

With increase in TrOC concentration from $50-100 \mu \mathrm{g} / \mathrm{L}, 8-28 \%$ reduction in removal of some resistant TrOCs was observed due to kinetic limitations. SA addition at a dose of $10 \mu \mathrm{M}$ significantly increased TrOC removal. Elevated dosages of SA $(50$ and $100 \mu \mathrm{M})$ could not improve TrOC removal efficiency further, but increased effluent toxicity, which may be attributed to the passage of unconsumed SA and phenoxyl radicals (highly reactive radicals generated from SA-oxidation by laccase) through the membrane to the effluent. Overall, the TrOC removal and treated effluent toxicity data suggested that a high dose of SA should be avoided.

\section{Acknowledgement}

The Australian Government is thanked for an international Postgraduate Research Scholarship $(\mathrm{PhD})$ award to Luong N. Nguyen. Novozymes Pty. Lt, Australia is thanked for the provision of laccase. This study has been funded by the GeoQuEST research center of the University of Wollongong.

\section{References}

[1] Ba, S., Jones, J.P., Cabana, H. 2014. Hybrid bioreactor (HBR) of hollow fiber microfilter membrane and cross-linked laccase aggregates eliminate aromatic pharmaceuticals in wastewaters. J. Hazard. Mater. 280, 662-670. 
[2] Camarero, S., Ibarra, D., Martínez, Á.T., Romero, J., Gutiérrez, A., del Río, J.C. 2007. Paper pulp delignification using laccase and natural mediators. Enzyme Microb. Technol. 40, 1264-1271.

[3] Cañas, A.I., Camarero, S. 2010. Laccases and their natural mediators: Biotechnological tools for sustainable eco-friendly processes. Biotechnol. Adv. 28, 694-705.

[4] Cristóvão, R.O., Tavares, A.P.M., Ribeiro, A.S., Loureiro, J.M., Boaventura, R.A.R., Macedo, E.A. 2008. Kinetic modelling and simulation of laccase catalyzed degradation of reactive textile dyes. Bioresour. Technol. 99, 4768-4774.

[5] d'Acunzo, F., Galli, C., Gentili, P., Sergi, F. 2006. Mechanistic and steric issues in the oxidation of phenolic and non-phenolic compounds by laccase or laccase-mediator systems. The case of bifunctional substrates. New J. Chem. 30, 583-591.

[6] de Boer, W., Folman, L.B., Klein Gunnewiek, P.J.A., Svensson, T., Bastviken, D., Öberg, G., del Rio, J.C., Boddy, L. 2010. Mechanism of antibacterial activity of the white-rot fungus Hypholoma fasciculare colonizing wood. Can. J. Microbiol. 56, 380-388.

[7] Escalona, I., de Grooth, J., Font, J., Nijmeijer, K. 2014. Removal of BPA by enzyme polymerization using NF membranes. J. Membr. Sci. 468, 192-201.

[8] Fillat, A., Colom, J.F., Vidal, T. 2010. A new approach to the biobleaching of flax pulp with laccase using natural mediators. Bioresour. Technol. 101, 4104-4110.

[9] Gaddum, J.H. 1949. Pharmacology. Oxford University Press, London.

[10] Hai, F.I., Nghiem, L.D., Modin, O. 2013. Biocatalytic membrane reactors: Removal of recalcitrant and emerging pollutants. In: Handbook of membrane reactors (ISBN: 9780857094155). Basile, A. (Eds.). Woodhead publishing. Cambridge, UK.

[11] Hai, F.I., Tessmer, K., Nguyen, L.N., Kang, J., Price, W.E., Nghiem, L.D. 2011. Removal of micropollutants by membrane bioreactor under temperature variation. J. Membr. Sci. 383, 144151. 
[12] Khlifi, R., Belbahri, L., Woodward, S., Ellouz, M., Dhouib, A., Sayadi, S., Mechichi, T. 2010.

Decolourization and detoxification of textile industry wastewater by the laccase-mediator system. Journal of Hazardous Materials. 175, 802-808.

[13] Kim, Y.-J., Nicell, J.A. 2006a. Laccase-catalysed oxidation of aqueous triclosan. J. Chem.Technol. Biotechnol. 81, 1344-1352.

[14] Kim, Y.-J., Nicell, J.A. 2006b. Laccase-catalyzed oxidation of bisphenol A with the aid of additives. Process Biochem. 41, 1029-1037.

[15] Lloret, L., Eibes, G., Lú-Chau, T.A., Moreira, M.T., Feijoo, G., Lema, J.M. 2010. Laccase-catalyzed degradation of anti-inflammatories and estrogens. Biochem Eng J. 51, 124-131.

[16] Loewe, S. 1953. The problem of synergism and antagonism of combined drugs. Arzneim- Forsch. 3, 285-290.

[17] Luna-Acosta, A., Saulnier, D., Pommier, M., Haffner, P., De Decker, S., Renault, T., ThomasGuyon, H. 2011. First evidence of a potential antibacterial activity involving a laccase-type enzyme of the phenoloxidase system in Pacific oyster Crassostrea gigas haemocytes. Fish Shellfish Immunol. 31, 795-800.

[18] Margot, J., Copin, P.-J., von Gunten, U., Barry, D.A., Holliger, C. 2015. Sulfamethoxazole and isoproturon degradation and detoxification by a laccase-mediator system: Influence of treatment conditions and mechanistic aspects. Biochem Eng J. 103, 47-59.

[19] Maruyama, T., Komatsu, C., Michizoe, J., Sakai, S., Goto, M. 2007. Laccase-mediated degradation and reduction of toxicity of the postharvest fungicide imazalil. Process Biochem. 42, 459-461.

[20] Mizuno, H., Hirai, H., Kawai, S., Nishida, T. 2009. Removal of estrogenic activity of isobutylparaben and n-butylparaben by laccase in the presence of 1-hydroxybenzotriazole. Biodegradation. 20, 533-539.

[21] Modin, O., Hai, F.I., Nghiem, L.D., Basile, A. 2014. Gas-diffusion, extractive, and biocatalytic membrane biological reactors. In: Membrane Biological reactors. Hai, F.I., Yamamoto, K., Lee, C.-H. (Eds.). IWA publishing. UK (ISBN:971780400655). 
[22] Mori, I.C., Arias-Barreiro, C.R., Koutsaftis, A., Ogo, A., Kawano, T., Yoshizuka, K., InayatHussain, S.H., Aoyama, I. 2015. Toxicity of tetramethylammonium hydroxide to aquatic organisms and its synergistic action with potassium iodide. Chemosphere. 120, 299-304.

[23] Nguyen, L.N., Hai, F.I., Kang, J., Leusch, F.D.L., Roddick, F., Magram, S.F., Price, W.E., Nghiem, L.D. 2014. Enhancement of trace organic contaminant degradation by crude enzyme extract from Trametes versicolor culture: Effect of mediator type and concentration. J. Taiwan Inst. Chem. Eng. $45,1855-1862$.

[24] Nguyen, L.N., Hai, F.I., Price, W.E., Kang, J., Leusch, F.D.L., Roddick, F., van de Merwe, J.P., Magram, S.F., Nghiem, L.D. 2015. Degradation of a broad spectrum of trace organic contaminants by an enzymatic membrane reactor: Complementary role of membrane retention and enzymatic degradation. Int. Biodeterior. Biodegrad. 99, 115-122.

[25] Parshetti, G.K., Parshetti, S.G., Telke, A.A., Kalyani, D.C., Doong, R.A., Govindwar, S.P. 2011. Biodegradation of Crystal Violet by Agrobacterium radiobacter. J Enviro Sci. 23, 1384-1393.

[26] Pipe, N.D., Brasier, C.M., Buck, K.W. 2000. Evolutionary Relationships of the Dutch Elm Disease Fungus Ophiostoma novo-ulmi to Other Ophiostoma Species Investigated by Restriction Fragment Length Polymorphism Analysis of the rDNA Region. J. Phytopathol. 148, 533-539.

[27] Richmond, C., Ujor, V., Ezeji, T.C. 2012. Impact of syringaldehyde on the growth of Clostridium beijerinckii NCIMB 8052 and butanol production. 3 Biotech. 2, 159-167.

[28] Schwarzenbach, R.P., Escher, B.I., Fenner, K., Hofstetter, T.B., Johnson, C.A., von Gunten, U., Wehrli, B. 2006. The Challenge of Micropollutants in Aquatic Systems. Science. 313, 1072-1077.

[29] Sørensen, H., Cedergreen, N., Skovgaard, I., Streibig, J. 2007. An isobole-based statistical model and test for synergism/antagonism in binary mixture toxicity experiments. Environ Ecol Stat. 14, 383397.

[30] van de Merwe, J., Leusch, F. 2015. A sensitive and high throughput bacterial luminescence assay for assessing aquatic toxicity - the BLT-Screen. Environ. Sci. Processes Impacts. In press. 
[31] Weng, S.-S., Ku, K.-L., Lai, H.-T. 2012. The implication of mediators for enhancement of laccase oxidation of sulfonamide antibiotics. Bioresour. Technol. 113, 259-264.

[32] Xu, F., Kulys, J.J., Duke, K., Li, K., Krikstopaitis, K., Deussen, H.-J.W., Abbate, E., Galinyte, V., Schneider, P. 2000. Redox chemistry in laccase-catalyzed oxidation of N-Hydroxy compounds. Appl. Environ. Microbiol. 66, 2052-2056.

[33] Yang, S., Hai, F.I., Nghiem, L.D., Price, W.E., Roddick, F., Moreira, M.T., Magram, S.F. 2013. Understanding the factors controlling the removal of trace organic contaminants by white-rot fungi and their lignin modifying enzymes: A critical review. Bioresour. Technol. 141, 97-108.

[34] Yu, X., Zeng, J., Zheng, Y., Chen, S. 2014. Effect of lignocellulose degradation products on microbial biomass and lipid production by the oleaginous yeast Cryptococcus curvatus. Process Biochem. 49, 457-465. 


\section{List of figures:}

Figure 1: Toxicity (\%) i.e., inhibition of bacterial luminescence (\%) of: (a) laccase ( $\mu \mathrm{M}(\mathrm{DMP})$ $/ \mathrm{min})$ and (b) $\mathrm{SA}(\mu \mathrm{M})$ in batch tests. Data presented as average \pm standard deviation $(\mathrm{n}=2$ independent measurements). Data presented as average \pm standard deviation ( $\mathrm{n}=2$ independent measurements). Data below the detection limit of the BLT-Screen (10\% inhibition of luminescence) have been included to highlight the low toxicity at low SA and laccase concentrations. Exclusion of these data makes results in identical slope and $\mathrm{R}^{2}$ values of these regressions.

Figure 2: Synergistic effect between laccase and SA toxicity (a) isobologram and (b) toxicity contour map showing 10, 20, 50, 70 and $95 \%$ toxicity profiles at varying concentrations of laccase activity $v s$. SA concentration.

Figure 3: Removal efficiency of 31 TrOCs by the laccase-EMR. Laccase activity was maintained at a range of 160 to $180 \mu \mathrm{M}_{(\mathrm{DMP})} /$ min by the addition of $400 \mu \mathrm{L}$ of the commercial laccase solution per liter of the reactor volume every $12 \mathrm{~h}$ (equivalent to a laccase dose of $46 \mathrm{mg} /$ $\mathrm{Ld}$ ). The EMR was operated for $72 \mathrm{~h}$ (i.e., $9 \mathrm{x}$ HRT). Data presented as average \pm standard deviation $(n=6)$.

Figure 4: Removal efficiency of non-phenolic compounds by the laccase-EMR: (a) with SA addition at a concentration of $10 \mu \mathrm{M}$ and TrOCs at a concentration of 5,50 and $100 \mu \mathrm{g} / \mathrm{L}$ of each compound, and (b) with SA addition at a concentration of 10,50 and $100 \mu \mathrm{M}$ and TrOCs at a concentration of $100 \mu \mathrm{g} / \mathrm{L}$ of each compound. Laccase activity was maintained at a range of 160 to $180 \mu \mathrm{M}_{(\mathrm{DMP})} / \mathrm{min}$ by the addition of $400 \mu \mathrm{L}$ of the commercial laccase solution per liter of the reactor volume every $12 \mathrm{~h}$ (equivalent to a laccase dose of $46 \mathrm{mg} / \mathrm{L} \mathrm{d}$ ). The EMR was operated for $72 \mathrm{~h}$ (i.e., $9 \times \mathrm{HRT})$. Data presented as average \pm standard deviation $(\mathrm{n}=6)$.

Figure 5: Fate of TrOCs (\%) during EMR operation with SA addition at a concentration of 10, 50 and $100 \mu \mathrm{M}$ and $\mathrm{TrOC}$ concentration of 50 and $100 \mu \mathrm{g} / \mathrm{L}$.

Figure 6: Comparison of toxicity following the EMR treatment at different TrOC and SA concentrations. The limit of detection of the toxicity assay was generally below $10 \%$ of inhibition values. A $20 \%$ inhibition of luminescence was considered to be a conservative value of the minimum response that could be quantified in the assay. The detection limit was 1 rTU. 

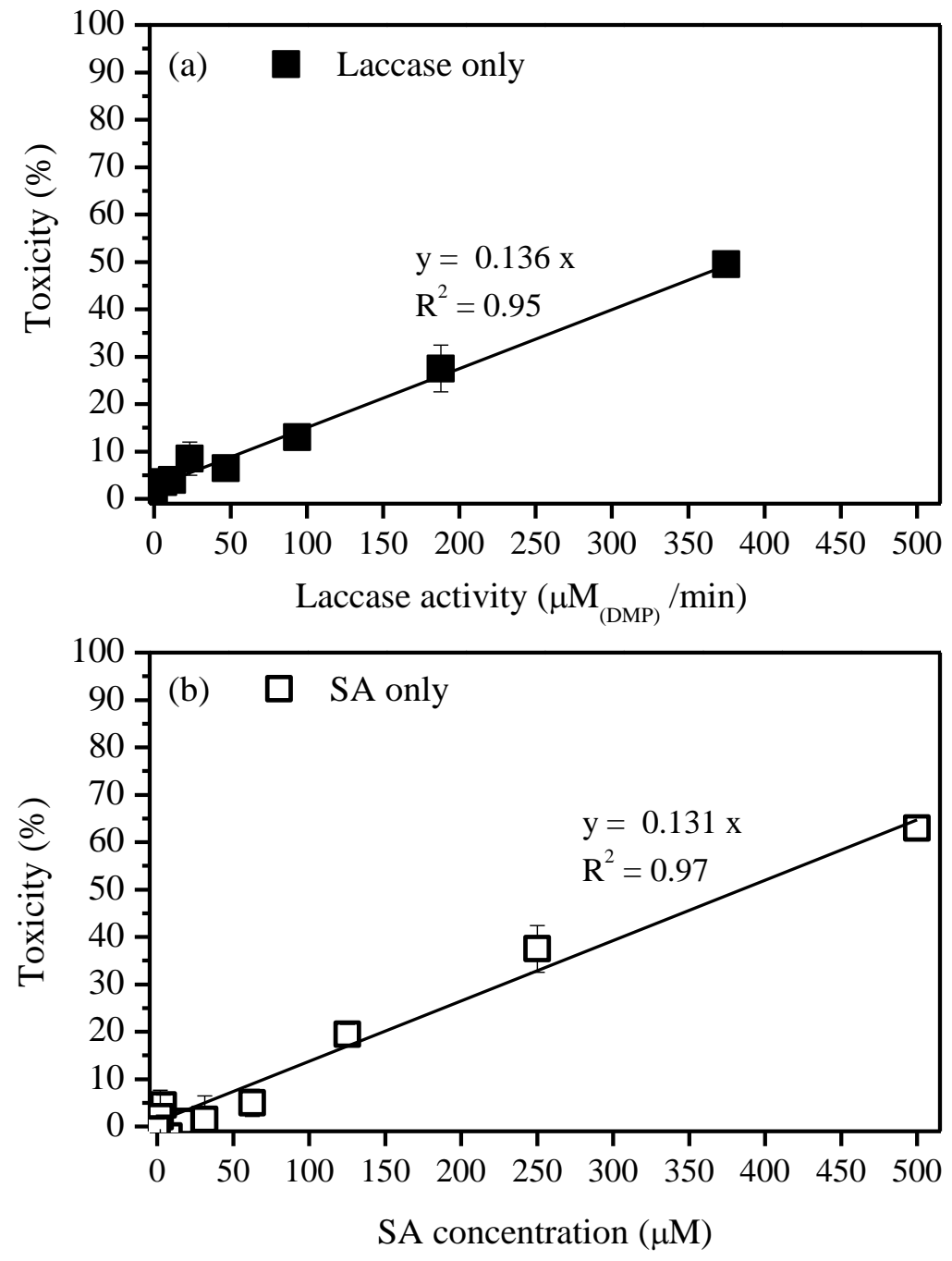

Figure 1 

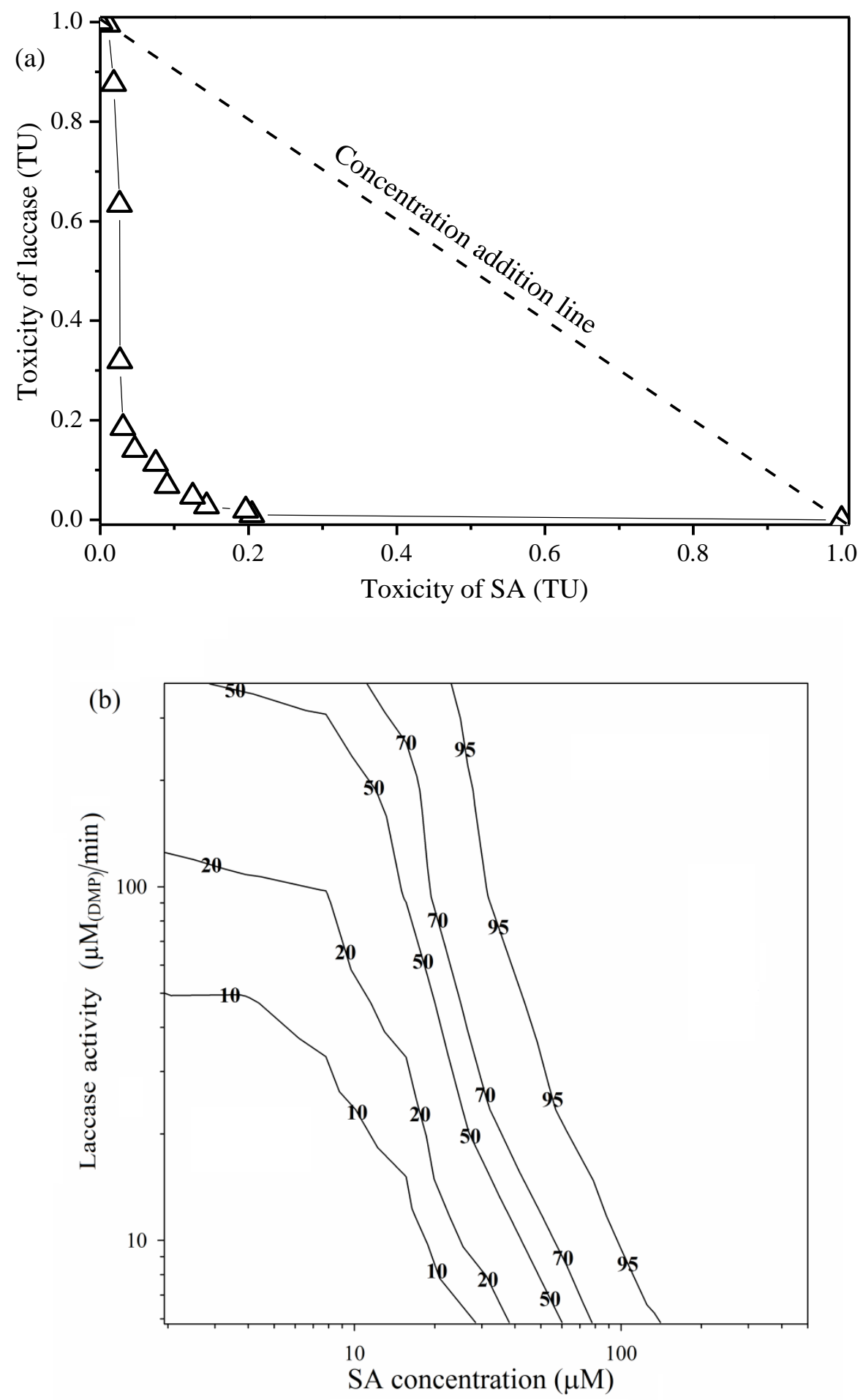

Figure 2 


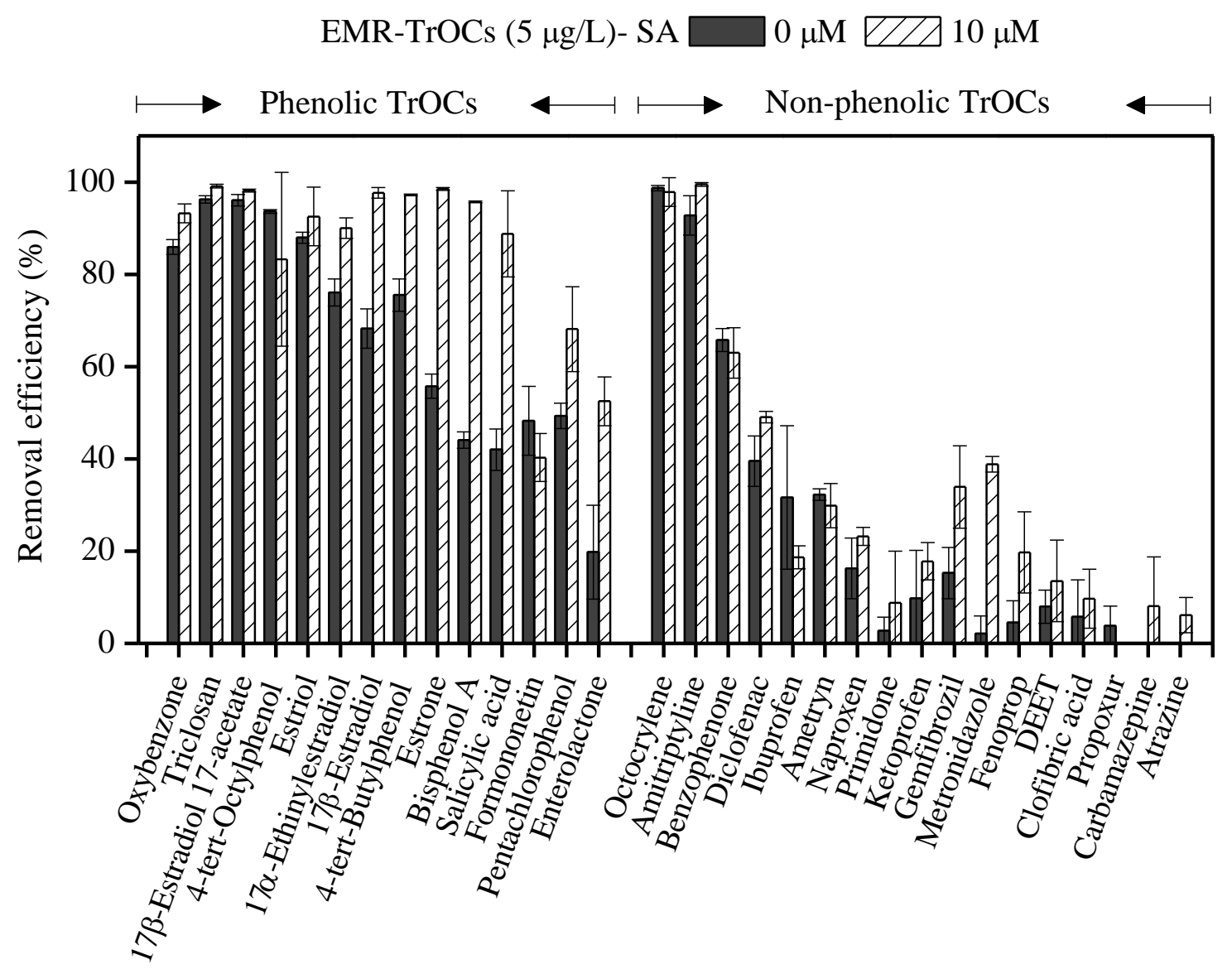

Figure 3 


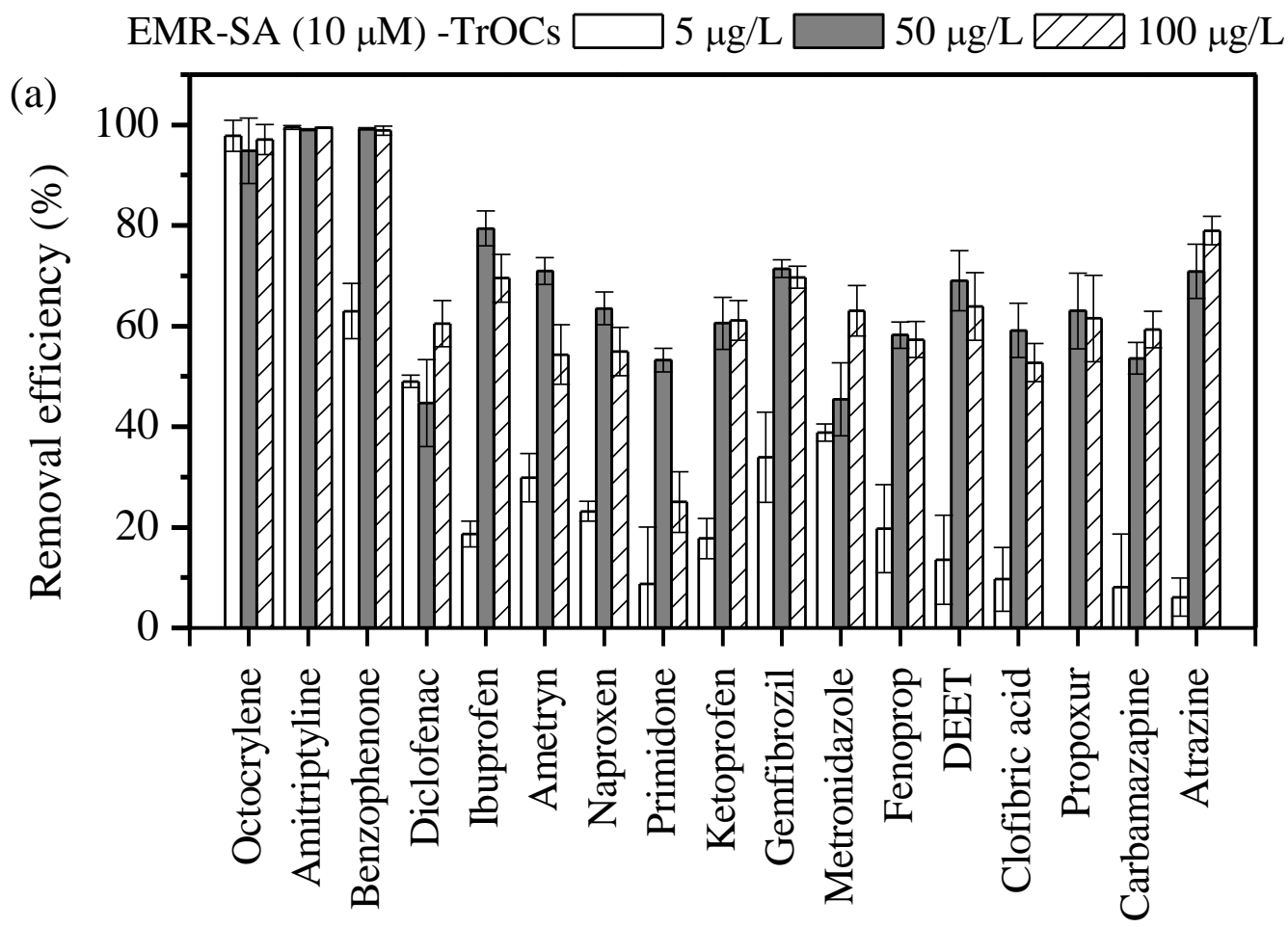

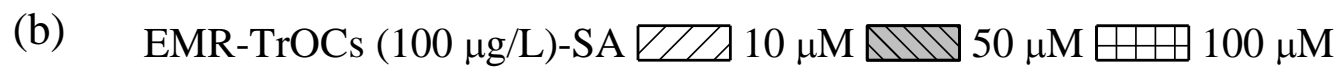

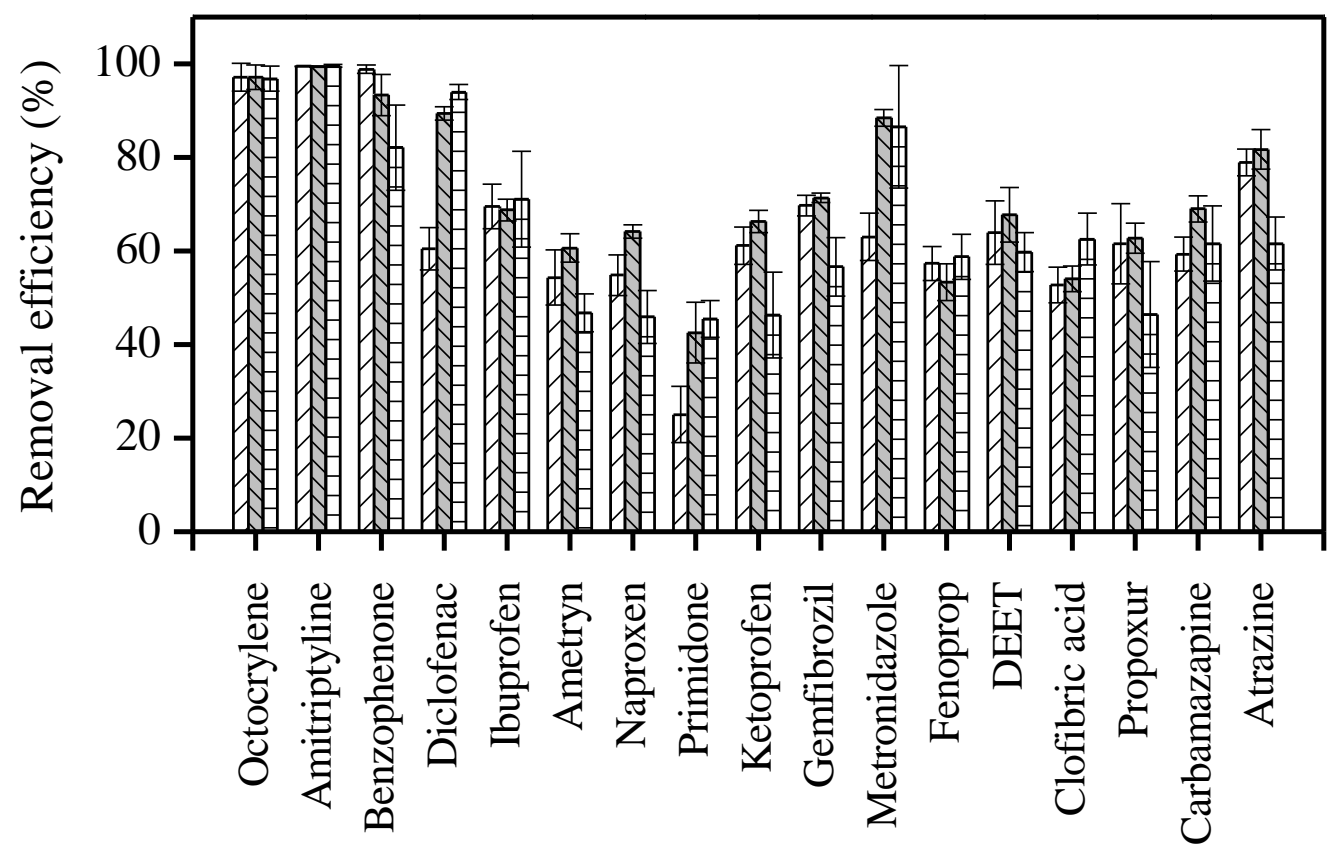


Figure 4

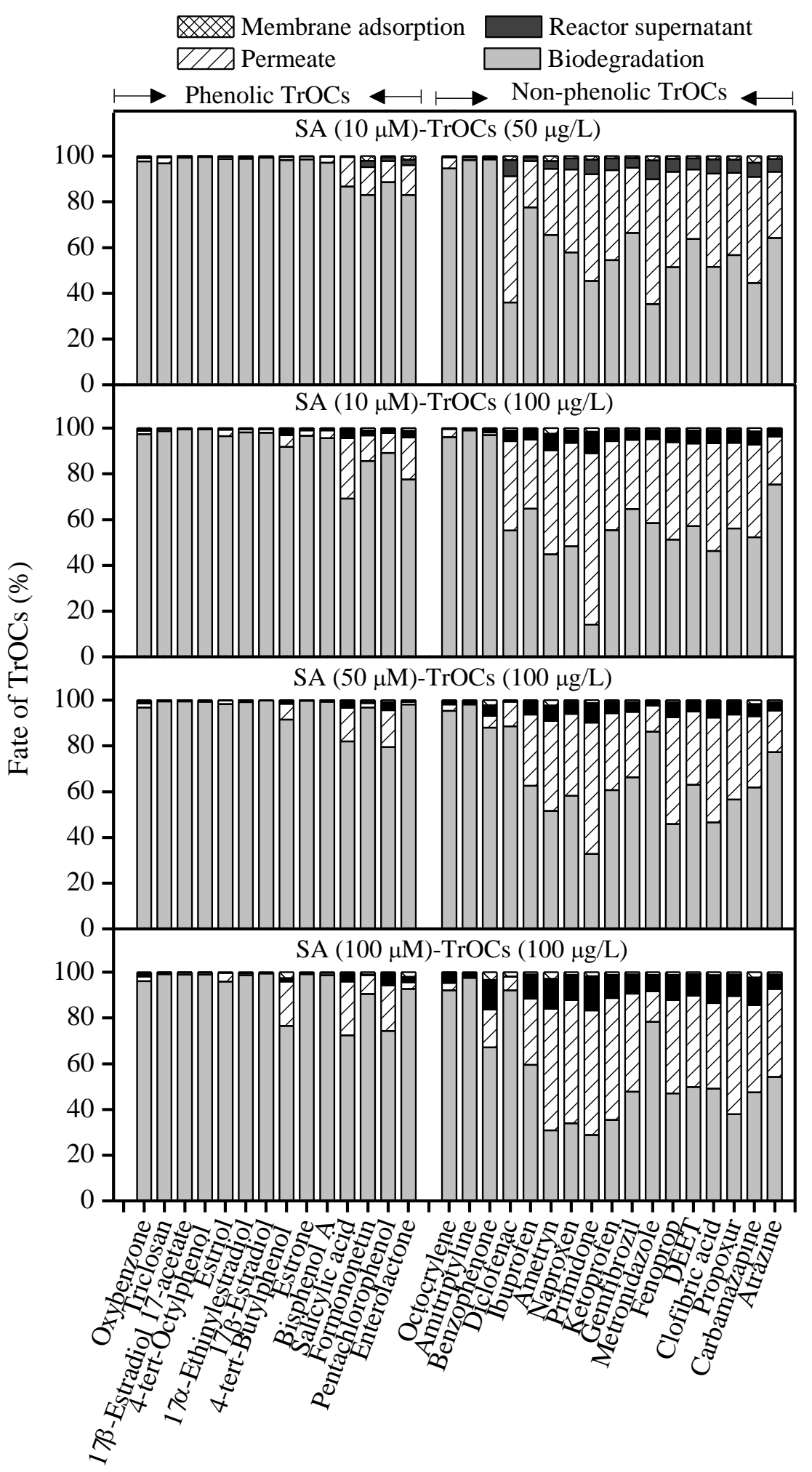


Figure 5

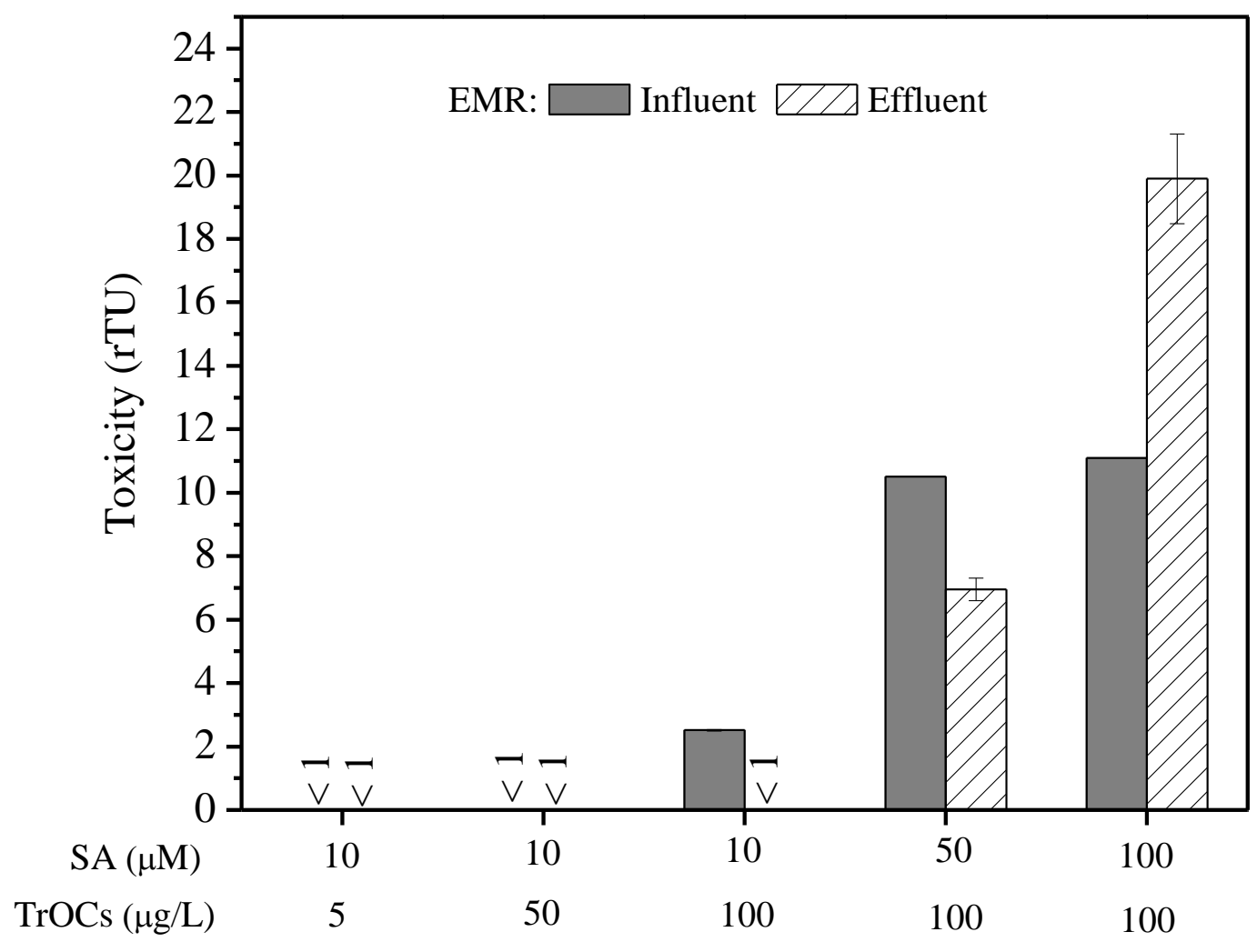




\section{Laccase - syringaldehyde - mediated degradation of trace organic contaminants in an enzymatic membrane reactor: Removal efficiency and effluent toxicity}

Luong N. Nguyen ${ }^{a}$, Jason P. van de Merwe ${ }^{\text {b }}$, Faisal I. Hai ${ }^{a *}$, Frederic D.L. Leusch ${ }^{\text {b }}$, Jinguo Kang a,c , William E. Price ${ }^{\mathrm{c}}$, Felicity Roddick ${ }^{\mathrm{d}}$, Saleh F. Magram ${ }^{\mathrm{e}}$, and Long D. Nghiem ${ }^{\mathrm{a}}$

${ }^{\text {a }}$ Strategic Water Infrastructure Lab, School of Civil, Mining and Environmental Engineering, University of Wollongong, Wollongong, NSW 2522, Australia.

${ }^{\mathrm{b}}$ Smart Water Research Centre, Australian Rivers Institute, School of Environment, Griffith University, QLD 4222, Australia

${ }^{\mathrm{c}}$ Strategic Water Infrastructure Lab, School of Chemistry, University of Wollongong, Wollongong, NSW 2522, Australia.

${ }^{\mathrm{d}}$ School of Civil, Environmental and Chemical Engineering, RMIT University, Melbourne, VIC 3001, Australia

${ }^{\mathrm{e}}$ Department of Civil Engineering, King Abdul Aziz University, Jeddah 21589, Saudi Arabia

*Corresponding author: Faisal I. Hai, E-mail: faisal@ uow.edu.au, Ph: + 61242213054

Table S1: Physicochemical properties of the selected trace organic contaminants (TrOCs) 


\begin{tabular}{|c|c|c|c|c|c|c|c|}
\hline Category & $\begin{array}{l}\text { Compound } \\
\text { (CAS number) }\end{array}$ & $\begin{array}{c}\text { Molecular } \\
\text { weight } \\
(\mathrm{g} / \mathrm{mol})\end{array}$ & $\begin{array}{l}\log \\
\mathrm{K}_{\mathrm{OW}}{ }^{2}\end{array}$ & $\begin{array}{l}\log D \\
(\mathrm{pH} 7)^{a}\end{array}$ & $\begin{array}{l}\text { Dissociati } \\
\text { on } \\
\text { constant } \\
(\mathrm{pKa})^{\mathrm{a}}\end{array}$ & $\begin{array}{l}\text { Limit of } \\
\text { detection } \\
(\mathrm{ng} / \mathrm{L})^{\mathrm{b}}\end{array}$ & Chemical structure \\
\hline \multirow{8}{*}{ 范 } & $\begin{array}{l}\text { Ibuprofen } \\
\left(\mathrm{C}_{13} \mathrm{H}_{18} \mathrm{O}_{2}\right) \\
(5687-27-1)\end{array}$ & 206.28 & $\begin{array}{c}3.50 \pm \\
0.23\end{array}$ & 0.94 & $\begin{array}{c}4.41 \pm \\
0.10\end{array}$ & 20 & \\
\hline & $\begin{array}{c}\text { Naproxen } \\
\left(\mathrm{C}_{14} \mathrm{H}_{14} \mathrm{O}_{3}\right) \\
(22204-53-1)\end{array}$ & 230.26 & $\begin{array}{c}2.88 \pm \\
0.24\end{array}$ & 0.73 & $\begin{array}{c}4.84 \pm \\
0.30\end{array}$ & 1 & \\
\hline & $\begin{array}{l}\text { Ketoprofen } \\
\left(\mathrm{C}_{16} \mathrm{H}_{14} \mathrm{O}_{3}\right) \\
(22071-15-4)\end{array}$ & 254.28 & $\begin{array}{c}2.91 \pm \\
0.33\end{array}$ & 0.19 & $\begin{array}{c}4.23 \pm \\
0.10\end{array}$ & 20 & \\
\hline & $\begin{array}{c}\text { Diclofenac } \\
\left(\mathrm{C}_{14} \mathrm{H}_{11} \mathrm{Cl}_{2} \mathrm{NO}_{2}\right) \\
(15307-86-5)\end{array}$ & 296.15 & $\begin{array}{c}4.55 \pm \\
0.57\end{array}$ & 1.77 & $\begin{array}{c}4.18 \pm \\
0.10 \\
\\
-2.26 \pm \\
0.50\end{array}$ & 5 & \\
\hline & $\begin{array}{c}\text { Primidone } \\
\left(\mathrm{C}_{12} \mathrm{H}_{14} \mathrm{~N}_{2} \mathrm{O}_{2}\right) \\
(125-33-7)\end{array}$ & 218.25 & $\begin{array}{c}0.83 \pm \\
0.50\end{array}$ & 0.83 & $\begin{array}{c}12.26 \pm \\
0.40 \\
-1.07 \pm \\
0.40\end{array}$ & 10 & \\
\hline & $\begin{array}{l}\text { Carbamazepine } \\
\left(\mathrm{C}_{15} \mathrm{H}_{12} \mathrm{~N}_{2} \mathrm{O}\right) \\
(298-46-4)\end{array}$ & 236.27 & $\begin{array}{c}1.89 \pm \\
0.59\end{array}$ & 1.89 & $\begin{array}{c}13.94 \pm \\
0.20 \\
-0.49 \pm \\
0.20\end{array}$ & 10 & $\mathrm{NH}_{2}$ \\
\hline & $\begin{array}{c}\text { Salicylic acid } \\
\left(\mathrm{C}_{7} \mathrm{H}_{6} \mathrm{O}_{3}\right) \\
(69-72-7)\end{array}$ & 138.12 & $\begin{array}{c}2.01 \pm \\
0.25\end{array}$ & -1.13 & $\begin{array}{c}3.01 \pm \\
0.10\end{array}$ & 1 & \\
\hline & $\begin{array}{c}\text { Metronidazole } \\
\left(\mathrm{C}_{6} \mathrm{H}_{9} \mathrm{~N}_{3} \mathrm{O}_{3}\right) \\
(443-48-1)\end{array}$ & 171.15 & $\begin{array}{c}-0.14 \pm \\
0.30\end{array}$ & -0.14 & $\begin{array}{c}14.44 \pm \\
0.10 \\
\\
2.58 \pm \\
0.34\end{array}$ & 20 & \\
\hline
\end{tabular}




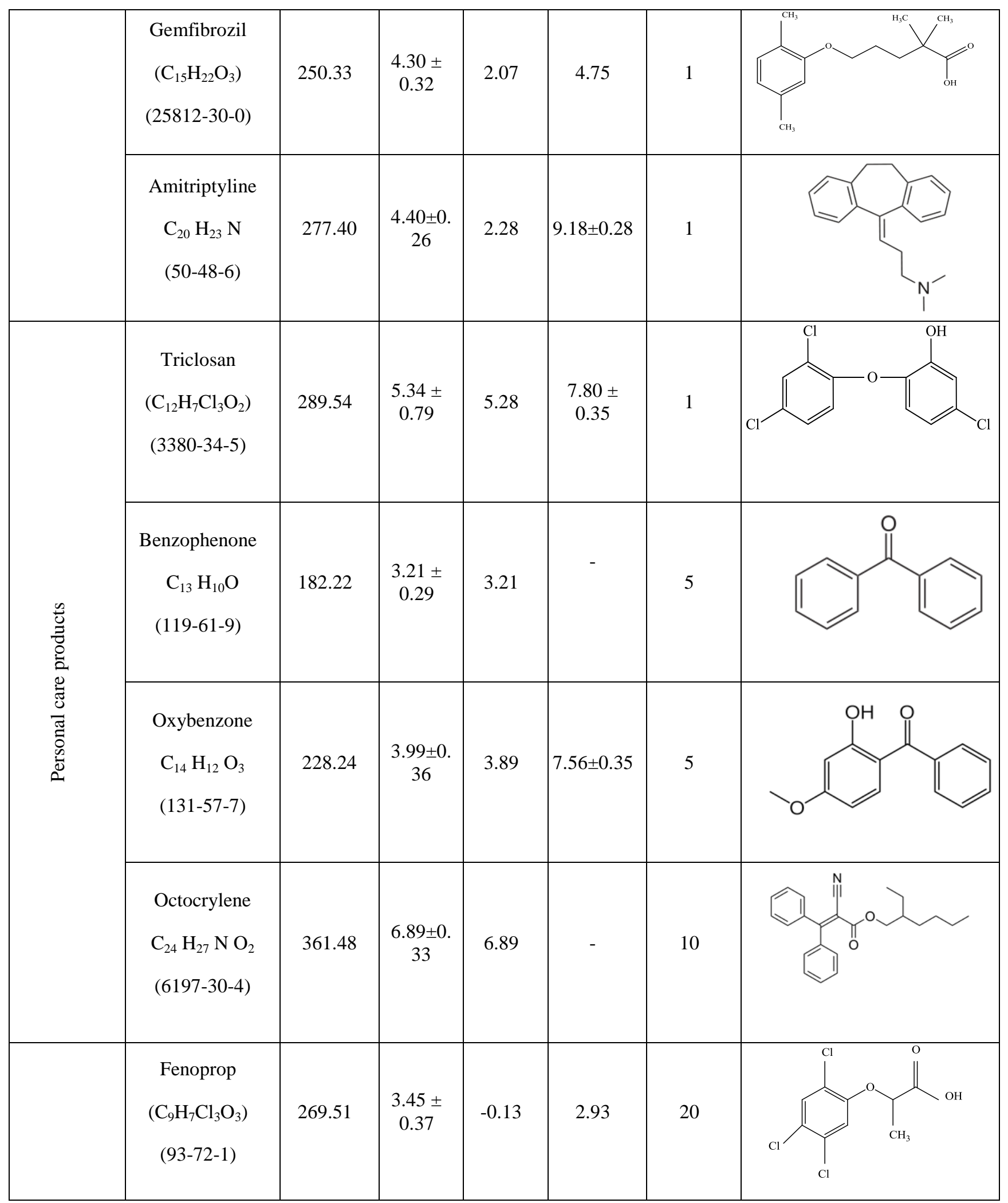




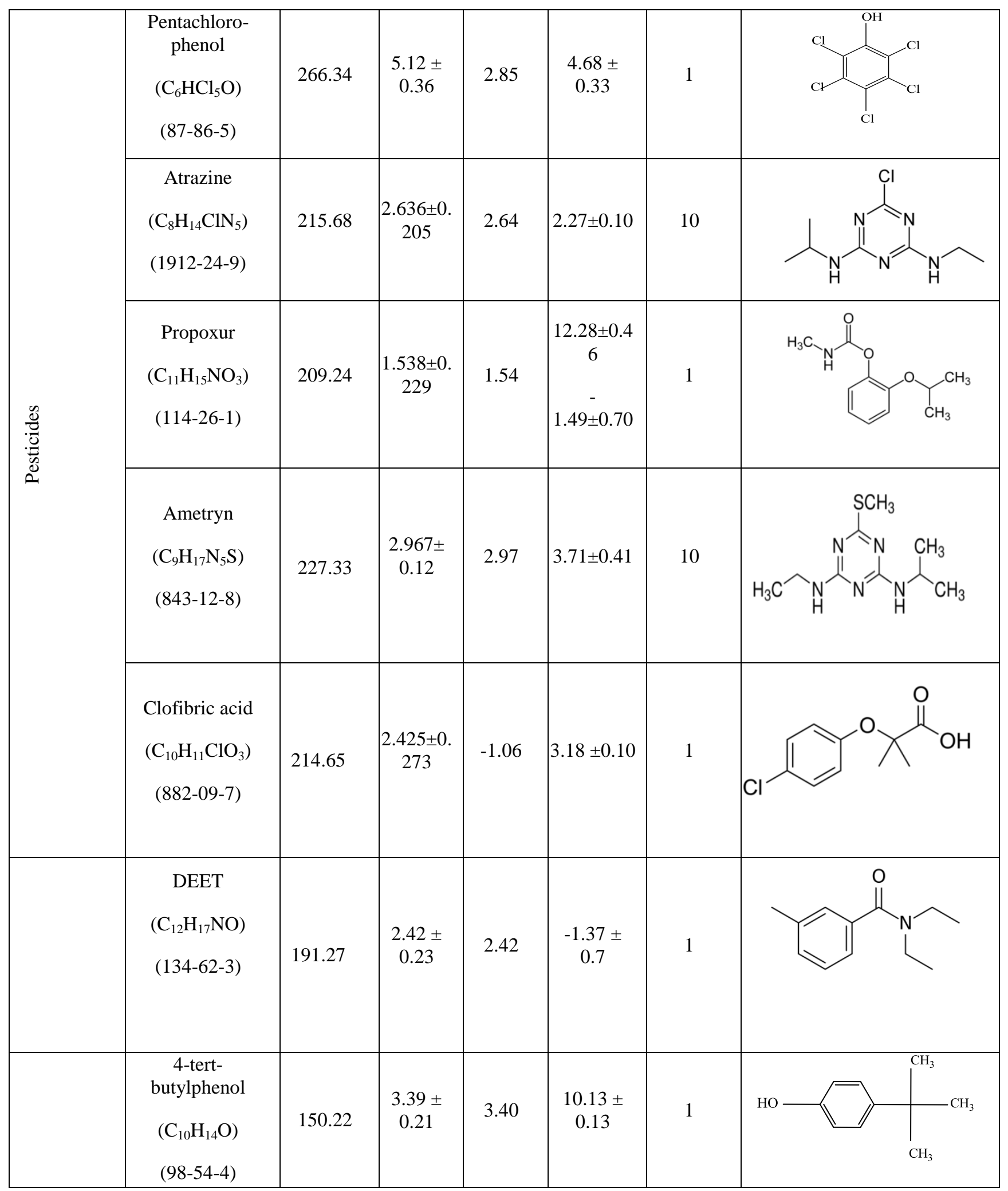




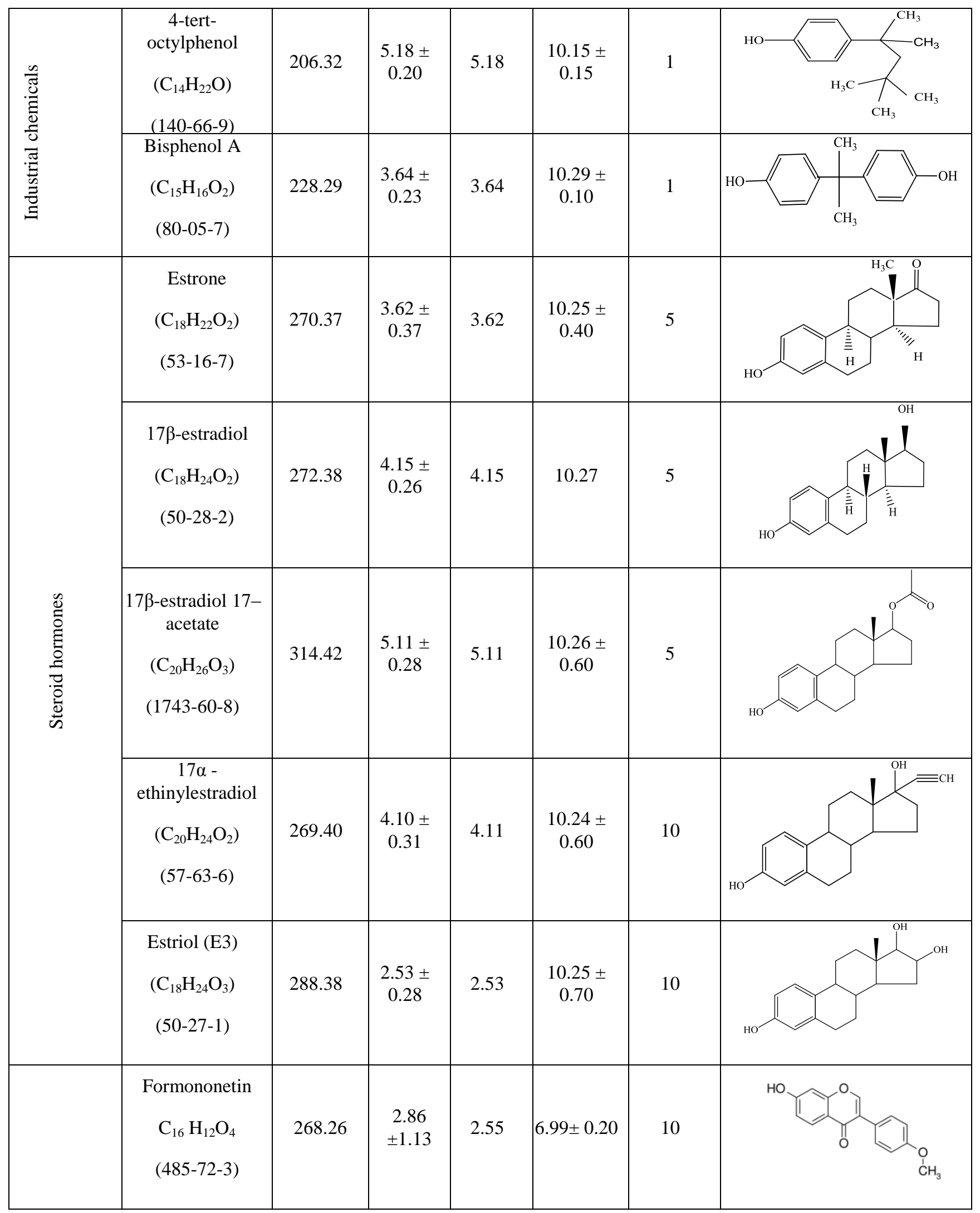




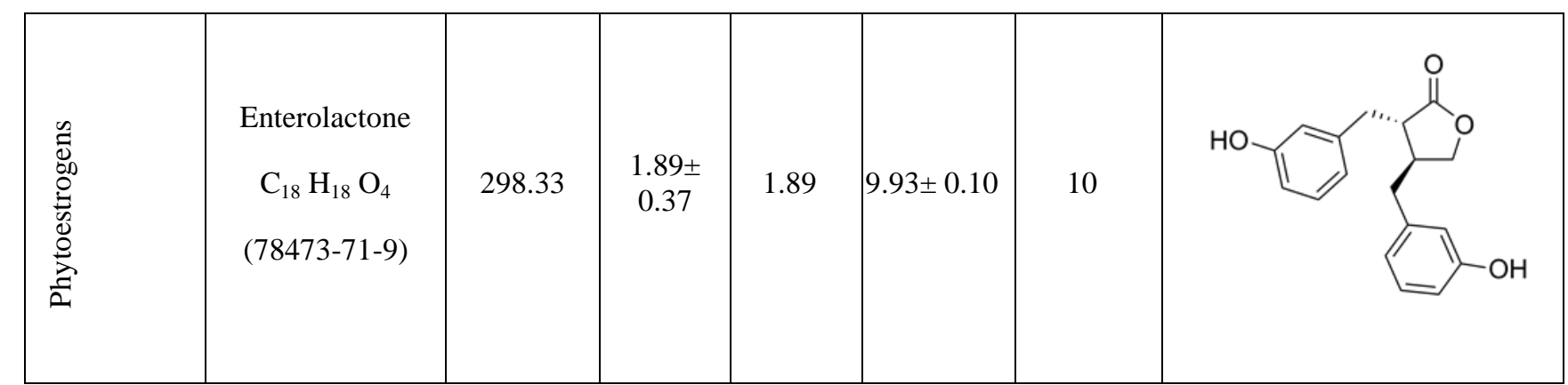

${ }^{a}$ Source: SciFinder database https://scifinder.cas.org/scifinder/view/scifinder/scifinderExplore.jsf

$\log D$ is $\operatorname{logarithm}$ of the distribution coefficient which is the ratio of the sum of concentrations of all forms of the compound (ionised and unionised) in octanol and water at a given $\mathrm{pH}$.

${ }^{b}$ Limit of detection (LOD) of the compounds during GC-MS analysis as described in Section 2.5.2. LOD is defined as the concentration of an analyte giving a signal to noise $(\mathrm{S} / \mathrm{N})$ ratio greater than 3 . The limit of reporting was determined using an $\mathrm{S} / \mathrm{N}$ ration of greater than 10 . 
Table S2: Sequence of EMR experiment

\begin{tabular}{cccc}
\hline Experiment ID & SA concentration $(\mu \mathrm{M})$ & TrOC concentration $(\mu \mathrm{g} / \mathrm{L})$ & Duration $(\mathrm{x}$ HRT $)$ \\
\hline 1 & 0 & 5 & 9 \\
\hline 2 & 10 & 5 & 9 \\
\hline 3 & 10 & 50 & 9 \\
\hline 4 & 10 & 100 & 9 \\
\hline 5 & 50 & 100 & 9 \\
\hline 6 & 100 & 100 & 9 \\
\hline
\end{tabular}




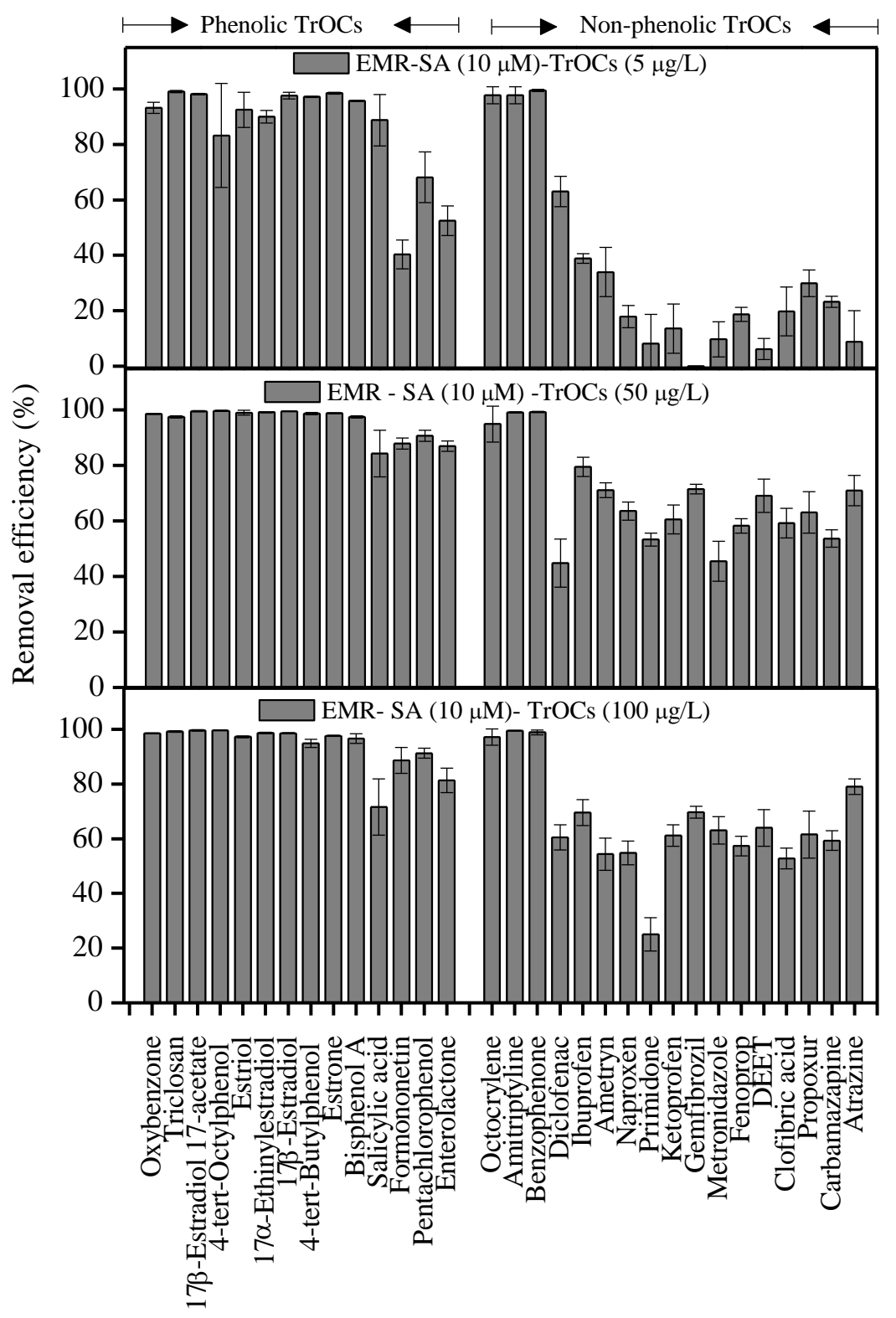

Figure S3: Removal efficiency of 31 TrOCs by laccase-EMR with SA addition at a concentration of $10 \mu \mathrm{M}$. The feed contained $31 \mathrm{TrOCs}$ at a concentration of 5, 50 and $100 \mu \mathrm{g} / \mathrm{L}$ of each compound. Laccase activity was maintained at the range from 160 to $180 \mu \mathrm{M}_{(\mathrm{DMP})} / \mathrm{min}$ by the addition of $400 \mu \mathrm{L}$ of the commercial laccase solution per liter of the reactor volume every $12 \mathrm{~h}$ (equivalent to a laccase dose of $46 \mathrm{mg} / \mathrm{Ld}$ ). The EMR was operated for $72 \mathrm{~h}$ (i.e., $9 \mathrm{x}$ HRT). Data presented as average \pm standard deviation $(n=6)$. 


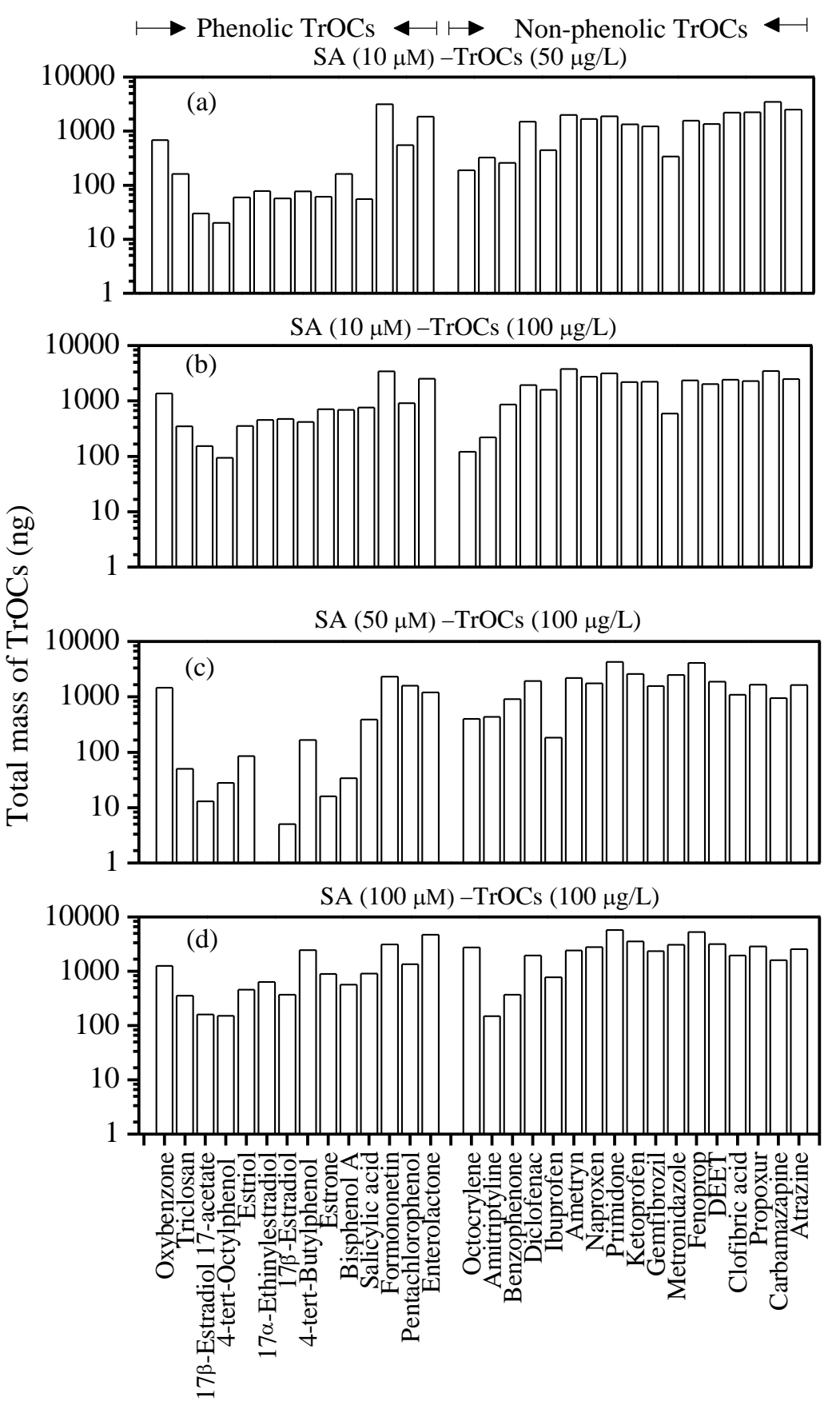

Figure S4: Adsorption of TrOCs on the membrane. TrOC extraction was conducted by membrane backwash with $1 \mathrm{~L}$ of Milli-Q water at a flux of $5 \mathrm{~L} / \mathrm{m}^{2} \mathrm{~h}$. 